Canadian Journal of Fisheries and Aquatic Sciences

Canadian Science Publishing

Journal canadien des sciences halieutiques et aquatiques

\title{
ASSESSING NATURAL MORTALITY OF BAY OF BISCAY ANCHOVY FROM SURVEY POPULATION AND BIOMASS ESTIMATES
}

\begin{tabular}{|r|l|}
\hline Journal: & Canadian Journal of Fisheries and Aquatic Sciences \\
\hline Manuscript ID & Cjfas-2015-0096.R2 \\
\hline Manuscript Type: & Article \\
\hline Date Submitted by the Author: & $30-$ Nov-2015 \\
\hline Complete List of Authors: & $\begin{array}{l}\text { URIARTE, ANDRES; AZTI, UIM } \\
\text { Ibaibarriaga, Leire; AZTI Tecnalia, Marine Research Unit } \\
\text { Pawlowski, Lionel; Ifremer } \\
\text { Masse, Jacques; Laboratoire d Ecologie Halieutique } \\
\text { Petitgas, Pierre; IFREMER } \\
\text { Santos, María; AZTI, UIM } \\
\text { Skagen, Dankert; -, - }\end{array}$ \\
\hline Keyword: & $\begin{array}{l}\text { CLUPEOID SPECIES < Organisms, natural mortality, Senescence, } \\
\text { Engraulidae, STOCK ASSESSMENT < General }\end{array}$ \\
\hline \multicolumn{2}{|c}{} \\
\hline
\end{tabular}


ASSESSING NATURAL MORTALITY OF BAY OF BISCAY ANCHOVY FROM SURVEY POPULATION AND BIOMASS ESTIMATES

5 By Andrés Uriarte ${ }^{1}$, Leire Ibaibarriaga ${ }^{2}$, Lionel Pawlowski $^{3}$, Jacques Massé $^{4}$, Pierre Petitgas $^{4}$, 6 María Santos $^{1}$ and Dankert Skagen ${ }^{5}$

$8{ }^{1}$ AZTI Tecnalia, Marine Research Division, Herrera Kaia Portualdea z/g; 20110 Pasaia, 9 Spain. Phone +34 943004816 / 800 Fax +34 9465725 55. auriarte@azti.es ; msantos@azti.es

$10{ }^{2}$ AZTI Tecnalia, Marine Research Division, Txatxarramendi Ugartea z/g, 48395 Sukarrieta, 11 Spain. Phone +34 946574000 / 800 Fax +34 9465725 55. libaibarriaga@azti.es

$12{ }^{3}$ IFREMER, Laboratoire Science et Technologie Halieutique, 8 rue François Toullec, 56100

13 Lorient, France. Phone +33 297873846 Fax +33 297873836. lionel.pawlowski@ifremer.fr

144 IFREMER, Nantes, P.O. Box 21105 F-44311 Nantes Cédex 03 France. Phone +33 15 (0)240374075.jacques.masse@ifremer.fr; Pierre.Petitgas@ifremer.fr

$16{ }^{5}$ Independent consultant, Fjellveien 96, N-5019 Bergen, Norway. Phone +47 93257452.

17 dankert@,dwsk.net

18 Corresponding author: Andrés Uriarte (auriarte@azti.es)

19 Abstract: The closure of the anchovy fishery in the Bay of Biscay between 2005 and 2010 due

20 to low biomass levels provided an opportunity to estimate natural mortality using data from

21 egg (DEPM) and acoustic surveys implemented for the assessment of this population since 
22 1987. Assuming that natural mortality (M) is constant over time and that catchability in both

23 surveys is equal for all ages, $M$ could be estimated using log-linear models on the series of

24 surveys of population numbers at age, and seasonal integrated stock assessments. The analysis

25 suggests $\mathrm{M}$ values of around 0.9 for a common natural mortality at all ages. However, we

26 found firm evidence that natural mortality at ages 2 and older (M2+) is markedly higher than

27 at age 1 (M1), which indicates senescent mortality, a possibility suggested a long time ago for

28 this type of short-lived species.

29 Keywords: Anchovy, natural mortality, senescence, Engraulidae.

31 Résumé: La fermeture de la pêche de l'anchois du Golfe de Gascogne entre 2005 et 2010, en

32 raison de la faible biomasse du stock, a été une opportunité pour estimer la mortalité naturelle

33 à partir de données de campagnes halieutiques issues de l'observation de la présence d'oeufs

34 (DEPM) et de mesures acoustiques, utilisées pour l'évaluation de cette population depuis

35 1987. En considérant que la mortalité naturelle est constante au cours du temps et que la

36 capturabilité des deux campagnes est identique pour tous les âges, la mortalité naturelle peut

37 être estimée par des modèles log-linéaires appliquées aux séries temporelles de nombres aux

38 âges issues des campagnes, et par des modèles d'évaluations de stock prenant en compte la

39 saison. L'analyse suggère des valeurs de $M$ autour de 0.9 comme mortalité naturelle courante

40 à tous les âges. Cependant, nous avons des éléments forts indicateurs que la mortalité aux

41 âges 2 et plus (M2+) est remarquablement plus forte qu'à l'âge 1 (M1) ce qui suppose un signe

42 de mortalité sénescente, une possibilité qui a déjà été évoquée il y a longtemps pour ce type

43 d'espèce à vie courte.

44 Mots clés: clupéidés (Clupeidae), Mortalité Naturelle, Senescence, Engraulidae, évaluations

45 des stocks 
47 Natural mortality (M) is a key population parameter scaling the population abundance and

48 fishing mortality estimates in standard (age-structured) assessment methods (Hilborn and

49 Walters 1992; Quinn and Deriso 1999; Gislason et al. 2010). However, it is difficult to

50 estimate because of the risk of confusion between natural (M) and fishing (F) mortality, or

51 between M and survey catchability at age (Vetter 1988; Quinn and Deriso 1999; Cotter et al.

52 2004; Wang et al. 2009). For this reason, the common approach is to apply a constant M

53 value (Hilborn and Walters 1992; Gislason et al. 2010; Jorgersen and Holt 2013). Such value

54 is often guessed according to the life span of the species. On other occasions, $\mathrm{M}$ is based on

55 published empirical relationships between $\mathrm{M}$ and life history parameters valid for comparable

56 groups of species and environments (Beverton 1992; Pauly 1980; Hoening 1983; Hewit \&

57 Hoening 2004). And sometimes it broadens to include size or age-dependent mortality as well

58 (Caddy 1991; Lorenzen 1996; Charnov et al. 2001; Charnov and Gillooly 2004; Gislason et 59 al. 2008, 2010).

61 In evolutionary theory, it is often suggested that the extrinsic mortality rate, attributable to

62 external factors like disease or predation, is the major factor that shapes the evolution of life 63 history (and indirectly, of senescence) through fitness optimization (Williams' hypothesis 64 1957- in Williams et al. 2006; Woodhead 1998; Reznick et al. 2002; Charnov et al. 2001; 65 Jorgensen and Holt 2013). Natural mortality of fish will change throughout the successive life 66 stages, from very high values in the egg, larval and juvenile stages to medium or low values 67 across their mature life span, before increasing again during senescence (Chen and Watanabe 68 1988; Charnov et al. 2001). Several biochemical mechanisms have been proposed to explain 69 the progressive deterioration of the physiological condition of organisms over time associated 
70 with senescence, such as the mutation accumulation theory or the antagonistic pleiotropy

71 theory (see reviews and discussions in Woodhead 1998; Williams et al. 2006; Golubev 2009).

72 Increasing mortality associated with senescence occurs at older ages (Vetter 1988; Woodhead

73 1998; Reznick et al. 2002; Gislason et al. 2010), and this is presumed to be particularly

74 noticeable in short-lived clupeoids (Beverton 1963). Measurements of senescent mortality, as

75 part of natural mortality, are difficult to obtain in the wild due to the many errors affecting the

76 observation of populations (Quinn and Deriso 1999; Gislason et al. 2010). Nevertheless,

77 various fish senescence patterns have been reported, ranging from the abrupt senescence of

78 salmon and eels (Woodhead 1998) or of some gobies (Caputo et al. 2002) to the gradual

79 senescence of guppies (Reznick et al. 2006), Nothobranchius furzeri (Terzibasi 2007),

80 gadoids (Sparholt et al. 2002; Nielsen et al. 2012) or herring (Tanasichuk 2000; Beverton et

81 al. 2004), and to the very slow or even negligible senescence of rockfish and carps (Reznick

82 et al. 2002).

84 The Bay of Biscay anchovy (Engraulis encrasicolus L.) is a fast growing and short-lived

85 species, fully mature at age 1, and rarely exceeding its third year of life (Uriarte et al. 1996;

86 Petitgas et al. 2010). In this region, anchovy is prey, along with other small pelagic fish, for

87 piscivorous species such as hake, megrim, sea bass, tunnidae or cetaceans, among others

88 (Preciado et al. 2008; Goñi et al. 2011; Lassalle et al. 2011; López-López et al. 2012). The

89 adult anchovy population is monitored yearly by two independent research surveys: an

90 acoustic survey (Massé et al. 1996, in press) and an egg survey applying the Daily Egg

91 Production Method - DEPM (Somarakis et al. 1994; Motos et al. 2005; Santos et al. 2011, in

92 press). Both surveys provide estimates of biomass and population numbers at age, which are

93 included in the assessment of this stock carried out by ICES (International Council for the 
94 Exploration of the Sea). A Bayesian two-stage biomass model (Ibaibarriaga et al. 2008) is

95 used for this assessment. Until 2004, ICA (Integrated Catch at age Analysis, Patterson and

96 Melvin 1996) was used (ICES 2005). Until 2013, natural mortality rate has been assumed to

97 be constant at 1.2 per year for all ages. This value was inferred in the nineties from direct

98 DEPM estimates of the population at age, assuming that they were absolute and unbiased

99 (Uriarte et al. 1996; Prouzet et al. 1999). While the Bayesian model presumes constant

100 catchability across ages and surveys, ICA calculated the catchability at age which was 50\%

101 higher for age 2 than for ages 1 or 3 (ICES 2005) in both surveys. This was not regarded as a

102 realistic outcome, taking into account the standard designs of both the DEPM and acoustic

103 surveys, which included non-selective fishing gears for adults (capable of catching sizes well

104 below minimum anchovy sizes in spring), and the sufficient spatial coverage of anchovy

105 distribution (ICES 2013). Certainly, an alternative explanation of the findings could be that

106 natural mortality is not constant over age.

108 Due to recruitment failures since 2001 and subsequent low biomass estimates (ICES 2013),

109 the anchovy fishery in the Bay of Biscay was closed between 2005 and 2010. However, since

110 scientific surveys were still ongoing during its closure, they provided a unique opportunity to

111 estimate the actual natural mortality rate and possible patterns in natural mortality at age.

112 Likewise, this closure allowed comparisons to be made between total mortality rates during

113 the closed period and those in the former period of exploitation, in order to get natural and

114 fishing mortality estimates under the assumption that no major changes in $\mathrm{M}$ occurred

115 between both periods (Gulland 1983; Vetter 1988; Cook 1994; Sinclair 2001). 
117 In this paper, several methods for estimating the natural mortality of the anchovy in the Bay

118 of Biscay were applied. First, a direct analysis of the variance (ANOVA) of total mortality

119 rate $(Z)$ derived from consecutive survey estimates of the population in numbers at age was

120 performed, where $\mathrm{Z}$ in the closure period was equivalent to the natural mortality rate (M).

121 Next, $M$ was estimated by regression of $\mathrm{Z}$ based on an indicator of fishing mortality (F)

122 derived from the ratio of catches to the survey estimates of abundance. Thus, $M$ is calculated

123 from the intercept of $\mathrm{Z}$ at zero fishing mortality, which includes information from surveys at

124 other F rates. Finally, an integrated assessment with a seasonal (half-year) separable fishing

125 mortality model was applied to catch and survey data in order to find natural mortality rates

126 and patterns that would optimize data fit, under the assumption of equal survey catchability at

127 age. This approach provides $\mathrm{M}$ estimates that best fit with all historical survey information

128 (including the two spring surveys and an acoustic recruitment index started in 2003 - Boyra et

129 al. 2013) and the historical catches at age. Therefore the successive methods gradually use a

130 larger amount of information. Furthermore, while the first two approaches assume log-normal

131 errors of the population at age estimates from surveys, the integrated assessment will in

132 addition allow for multinomial errors.

135 2. Materials and Methods

137 2.1. Surveys 
139 Estimates of population numbers at age are available from the acoustic (PELGAS -Ifremer-

140 Massé et al. 1996, in press) and DEPM (BIOMAN-AZTI- Somarakis et al. 1994; Motos et al.

141 2005; Santos et al. in press) surveys carried out yearly in May since 1987 and 1989,

142 respectively (ICES 2013). DEPM surveys since 1987 and acoustic surveys since 2000 have

143 reported population at ages 1, 2 and 3+ (with $3+$ referring to fish of age 3 and older), while

144 earlier acoustic estimates have reported total biomass and, only occasionally, population

145 numbers at age 1 and 2+ (in 1989, 1991, 1992 and 1997).

146 In addition, since 2003, an autumn survey has been carried out to provide an acoustic index of

147 juvenile anchovy abundance (Boyra et al. 2013). This was used as auxiliary information on

148 the level of recruitment at age 0 in the integrated assessment.

150 2.2. Direct total (Z) and natural (M) mortality estimates.

151 In a cohort of $N$ fishes at age $a$ in year $y\left(N_{a y}\right)$ subject to an annual mortality rate $\mathrm{Z}$, the

152 survivors into the next year will be $N_{a+1, y+1}=N_{a, y} e^{-Z_{a, y}}$.

153 Let $U_{a, y, s}$ denote the number of individuals at age $a$ in year $y$ estimated from survey $s$.

154 Provided this index is proportional to the true population abundance $(N)$ by a catchability 155 coefficient $(\boldsymbol{Q})$, and subject to a log-normal observation error common to all ages $\left(U_{a, y, s}=\right.$ $\left.156 Q_{a, s} N_{a, y} e^{\varepsilon^{\prime} s, y}\right)$, then the $\log$ of the ratio of successive age classes estimates in consecutive 157 years is an estimate of the total mortality at age $a$ in year $y$ from survey $s, Z_{a, y, s}$ modified by 158 the change in catchability:

$$
\hat{Z}_{a, y, s}=\ln \left[\frac{U_{a, y, s}}{U_{a+1, y+1, s}}\right]=\ln \left[\frac{N_{a, y} \cdot Q_{a, s} \cdot \exp \left(\varepsilon_{s, y}^{\prime}\right)}{N_{a+1, y+1} \cdot Q_{a+1, s} \cdot \exp \left(\varepsilon_{s, y+1}^{\prime}\right)}\right]=Z_{a, y}+\ln \left[\frac{Q_{a, s}}{Q_{a+1, s}}\right]+\varepsilon_{s, y}
$$


160 We refer to this as a $Z$ estimate. $Z$ estimates are further split into the natural and fishing

161 mortality components:

$162 \hat{Z}_{a, y, s}=\ln \left[\frac{U_{a, y, s}}{U_{a+1, y+1, s}}\right]=F_{a, y}+M_{a, y}+\ln \left[\frac{Q_{a, s}}{Q_{a+1, s}}\right]+\varepsilon_{y, s}$ Equation 1

163 Three $\mathrm{Z}$ estimates are derived: $\mathrm{Z} 1+$, from ages $1+$ to $2+$; $\mathrm{Z} 1$, from age 1 to 2 ; and $\mathrm{Z} 2+$, from 164 ages $2+$ to $3+$. Notice that $\mathrm{Z1}+$ will generally be closer to the $\mathrm{Z}$ of the most abundant age 165 classes (in this case, age 1). Since surveys are carried out at spawning time in May, Z 166 estimates refer to mortality rates from May to May. These estimates rely on two assumptions:

167 1) catchability is similar over age, and 2) survey observation errors follow log-normal 168 distribution and are of similar average magnitude in both surveys.

169 Consistency of the $\mathrm{Z}$ estimates by survey depending on fishing or closure periods was tested 170 by analysis of variance. Year, survey type (DEPM or acoustic), age (1 or $2+$ ) and fishing 171 period (closed or open fishery) were taken as factor variables, under the terms Year and 172 Survey and Old and Fishing, respectively.

174 We first tested, using ANOVA, the consistency of $Z$ estimates by survey across years for all 175 ages

$176 \hat{Z}_{a, y, s}=$ Year $_{y}+$ Survey $+[$ Old $]+\varepsilon$ (Model A1, Equation 2)

177 Old is in brackets because it only applies in the joint analysis of $Z 1$ and $Z 2+$. As the year 178 factor will cover the inter-annual variability in $\mathrm{Z}$ due to either natural (ecological) or fishing 179 causes, the former analysis should serve to assess whether or not the $\mathrm{Z}$ estimates provided by 180 the two surveys are consistent. This was checked by testing the statistical significance of the 181 Survey factor and, for the analysis by age, of the Survey * Old first order interaction. 
183 Next, we tested the effect of closure on the overall and age-dependent $Z$ values, which during 184 the closure period, will be our direct estimate of the natural mortality rate (M):

186 As before, Old only applies when analyzing $Z_{1}$ and $Z_{2+}$ together, but not when dealing with $187 \mathrm{Z}_{1+}$. Interactions are the potential first and second order interactions of the former variables, 188 which were initially checked. Finally, $\varepsilon$ is assumed to be a normal random variable with 189 constant variance common to all ages, years and surveys.

\subsection{Natural mortality estimates from linear models}

193 In order to make use of the whole dataset for the estimation of $M$ through a linear model, an

194 indicator of the fishing intensity for each year was obtained from the ratio of the catches 195 between surveys and the mean abundance of the cohort between surveys. This follows from 196 the catch equation:

$197 \quad F_{a, y}=\frac{C_{a, y}}{N_{a, y}}==\frac{C_{a, y}}{N_{a, y, s} \cdot\left(1-e^{-Z_{a, y, s}}\right) / Z_{a, y, s}}=\frac{C_{a, y}}{U_{a, y, s} \cdot\left(1-e^{-Z_{a, y, s}}\right) / Z_{a, y, s}} \cdot Q_{s}=R C \cdot Q_{s} \quad$ Equation 4

198 where the coefficient of proportionality of the Relative Catches over survey estimates $(R C)$ to

$199 F$ equals the catchability coefficient of the surveys (assumed constant across ages) $\left(Q_{s}\right)$. If

200 RC can be estimated then it can be used to calculate $M$ from Equation 1, as the intercept of the

201 linear model. However, the problem with this approach is that the fitted $Z$ will appear in the 
202 independent covariate $(R C)$. In order to avoid this, we considered two alternative formulations

203 of $R C$ and checked the sensitivity to them:

204 RCSurvey $2_{a, y}=\frac{C_{a, y}}{\left(U_{a, y, s}+U_{a+1, y+1, s}\right) / 2}$

Equation 5

$205 \quad$ RCJoint $2_{a, y}=\frac{C_{a, y}}{\sum_{s}\left(U_{a, y, s}+U_{a+1, y+1, s}\right) / 4}$

Equation 6

206 The first RC estimator provides an estimate by survey (RCSurvey2) using as denominator the

207 arithmetic mean of the abundances provided by the survey at the beginning and end of the $\mathrm{Z}$

208 estimate period. The second estimator RCJoint 2 provides a single joint indicator of fishing

209 intensity for each year from both surveys together, by taking as denominator the average

210 population provided by both surveys during the same period. In the latter case the analysis

211 will be restricted to the years when both surveys were carried out in parallel, so that the two $Z_{s}$

212 estimates of the year will be linked by the same $R C J$ oint estimate.

213 In all cases, the catches considered are those between May 15 of year $y$ and May 15 of year

$214 y+1$, for the ages $a$ and $a+1$ in each respective year. Catches at age (in numbers) with their

215 mean weights are reported by season in ICES until the closure of the fishery in 2005 (ICES

216 2005) and, more recently, in WGHANSA reports (ICES2013).

218 The following linear model was statistically tested for the different potential significant 219 coefficients:

$$
\hat{Z}_{a, y, s}=M_{a, y, s}+F_{a, y, s}+\varepsilon_{a, y}=M+\left[\text { Old }_{a}\right]+Q_{s} \cdot R C_{a, y}+\text { Survey }+ \text { Interact }+\varepsilon_{a, y, s}
$$


222 With $\boldsymbol{M}$ (natural mortality) being the intercept either at age 1 (M1) or for all ages together 223 (M1+) - depending on the subset of data being analyzed - Old is now a dummy variable, being 2240 for age 1 and 1 for age $2+$. This term will indicate the increase of natural mortality in fish of 225 age $2+$ relative to $M$ at age 1 (M1), for the joint analysis of $Z_{1}$ and $Z_{2+}$. $R C$ accounts for the 226 Relative Catches between surveys of the respective age $a$ in year $y$, and coefficient $\boldsymbol{Q}_{s}$ 227 accounts for proportionality of $\boldsymbol{R C}$ to fishing mortality F. Survey is a dummy variable, being 2280 for DEPM and 1 for acoustics, and this term will reflect any potential effect of the acoustic 229 survey relative to the DEPM on Z estimates. Interact are the potential first and second order 230 interactions of the former variables, which were initially checked.

231 For the joint analysis of $\mathrm{Z}$ by age ( $\mathrm{Z} 1$ and $\mathrm{Z2}+$ ), our assumption about catchability, constant 232 across age and necessary to estimate $\mathrm{Z}$, implies that the first or second order interactions 233 referring to the slope changing by age are not significant as the slope coefficient is the 234 catchability of the survey. Secondly, the intercepts reflecting $M$ are population parameters 235 which should be similarly estimated by the surveys. As such, first order interactions of 236 intercepts with surveys should not be significant. Therefore, the only interaction which could 237 be significant is that of the slopes by survey, which would correspond with the common 238 assumptions in most assessments of different catchabilities by survey. We will refer to the 239 two-slope model as the one allowing different slopes on RCSurvey2 by survey (but with 240 constant slopes across ages), while we will refer to the single slope model as the one forcing a 241 common slope for both surveys.

243 For the ANOVA analysis associated to all analyses above Type III errors were used. 
246 Finally, an integrated catch at age analysis with a seasonal (half-yearly) separable fishing

247 mortality model was applied to the catch and survey data currently used by ICES for the

248 assessment of this fishery (ICES 2013): Catches in tons and at age on a half-yearly basis,

249 spring surveys; Acoustic and DEPM estimates of total biomass (tons) and populations at age

250 (numbers); and finally, an acoustic survey on juveniles (JUVENA Survey index, started in

2512003 , which is used to tune the recruitment at age 1 with a power catchability function). The

252 purpose, as before, was to check what levels and patterns of natural mortality at age optimize

253 an integrated assessment, under the assumption of equal catchability at all ages in the surveys.

254 Natural mortality by age was applied either to a calendar year, going from January to

255 December or from July to June (the latter was checked because the main surveys are carried

256 out in May, i.e. closer to July than to January). The model was fitted using two different

257 approaches: the first one assumes, as before, that observations (catches or survey estimates in

258 biomass and by age) are subject to log-normal errors and the objective function is a direct

259 minimization of a weighted sum of squared residuals (WSSQ fitting - like in ICA analysis -

260 Patterson and Melvin 1996); the second approach is similar to the former one except that it

261 assumes that all age disaggregated data (catches and population at age estimates) are subject

262 to multinomial errors and hence are entered as percentages at ages 1,2 and $3+$. In the latter

263 case, model fitting is achieved by maximization of the log-likelihood (using log-likelihood

264 ratios - LLHR fitting). Given the general agreement in both surveys in terms of percentages at

265 age, and the poorer agreement in terms of biomass trends (ICES 2013), it seems that the

266 multinomial approach for indexes at age is probably a suitable way to deal with the type of

267 errors associated with survey observations. Details of the model's fitted objective functions

268 are given in Appendix A. The two modeling approaches were run in Microsoft Excel, using

269 Solver for objective function optimization. Convergence was verified using different starting

270 parameter values and likelihood of fitted models was calculated (see Appendix). Confidence 
271 intervals for natural mortality estimates were obtained using the profile likelihood method.

272 Based on the likelihood ratio test, the $95 \%$ confidence interval around the joint optimum of

$273 \hat{M} 1$ and $\hat{M} 2+$ is defined as the pairs of M1 and M2+ which satisfy the following inequality:

$274 \ln \left(L(\theta, \hat{M} 1, \hat{M} 2+)-\ln \left(L(\theta, M 1, M 2+) \leq \frac{1}{2} \chi_{2}^{2}(.95)\right.\right.$

Equation 8

275 Where $L(\hat{\theta}, \hat{M} 1, \hat{M} 2+)$ represents the likelihood at the optimum of M1 and M2+ and every

276 other parameter $(\hat{\theta})$, and $\ln (L(\hat{\theta}, M 1, M 2+)$ is the likelihood for any selected alternative of

277 fixed M1 and M2+ parameters (for the optimum of the remaining parameters - $\theta$ ). And

$278 \chi_{2}^{2}(.95)$ is the 0.95 percentile of the Chi-square with 2 degrees of freedom (i.e. 5.9915).

279 Confidence intervals for M1+ were also deduced from Equation 8 applied to a single M

280 parameter and Chi-square with 1 degree of freedom.

281 In order to compare the different fitted models, we used the corrected Akaike's Information

282 Criterion (AICc), estimated as:

$283 \quad \mathrm{AICc}=-2 * \ln ($ likelihood $)+2 * \mathrm{~K}+(2 * \mathrm{~K} *(\mathrm{~K}+1)) /(\mathrm{n}-\mathrm{K}-1)$,

Equation 9

284 with $\mathrm{K}$ being the number of parameters and $\mathrm{n}$ being the number of observations.

$286 \quad 2.4$ Sensitivity analysis

287 Sensitivity to some observations, that looked noisy at first sight and might have become too

288 influential for the particular methods applied, was tested by including and excluding such data

289 (when excluded we will refer to the subset of data). For raw data direct analysis during the

290 closure period (2005-2010), the 2005 and 2006 survey data resulted in negative $\mathrm{Z}$ estimates

291 between them, indicating that either 2005 estimates were too low or 2006 estimates too high. 
292 As for the linear models, years with high RC values (above 0.8) were considered unlikely to

293 be actually happening (due to the difficulty of producing such a fishing impact) which led us

294 to suspect some noisy, excessively low biomass estimates from the surveys during those

295 years. In addition, years 2011 and 2012 were checked for sensitivity as they resulted in

296 extremely different $\mathrm{Z}$ estimates by survey due to a large discrepancy in the 2012 biomass

297 estimates (ICES 2013). For the integrated assessment, analyzing sensitivity to the

298 inclusion/exclusion of the 2012 survey biomass estimates was considered sufficient (the year

299 of maximum biomass divergence - ICES 2013).

301 Furthermore, we tested the sensitivity of our results to a maximum potential level of errors in

302 age determination from otoliths. Even though the current ageing method is perceived to be

303 unbiased (Uriarte et al. in press), the actual level of error is unknown. Using expert advice, a

304 maximum of a 5\% level of ageing errors among contiguous age groups (from ages 1 to $3+$ )

305 was evaluated. Larger errors were considered unlikely and were not compatible with data.

306 Determination of age 0 was considered fully accurate. In addition, given the low percentage

307 of age 3 in surveys and catches, age 2 errors were considered to occur more often with age 1

308 (in $80 \%$ of cases) than with age 3 (only $20 \%$ ). The tested matrix for age determination error

309 (E) is shown in Table 1. Given a vector with the observed (assigned) age composition A

$310(1 * 4)$ of a survey or catches, the corrected estimates of the age composition $\mathbf{C}(1 * 4)$ are

311 deduced in matrix notation as:

$$
\mathbf{C}=\mathbf{A} \cdot \mathbf{E}^{-1}
$$

Equation 10

313 Corrections were not allowed to reduce the size of any age class below $20 \%$ of its original

314 value (before correction) and ad hoc changes were applied to ensure those minimums (by

315 restoring enough numbers from the contiguous age class in proportion to the removals 
316 produced on the original amount so as to still allow $20 \%$ of the starting amount). As for the

317 catches, corrections were applied to international catches separately over three periods: before

318 surveys (January - mid-May), after surveys (mid-May - June) and in the second half of the 319 year.

\section{Results}

a) Direct $\mathrm{Z}$ and $\mathrm{M}$ estimates (Model $\mathrm{A}$ )

323 The series of $Z$ estimates by survey show a large inter-annual variability (Figure 1). Z

324 estimates did not differ statistically between surveys ( $p>0.95$ for $Z 1+$ and $p>0.12$ for the $Z$ by 325 age, Model A1). During the 2005-2009 closure, Z estimates (proxy of M1+) were markedly 326 lower on average $(0.81, \mathrm{CV}=13 \%)$ than during fishing periods (1.66, $\mathrm{CV}=9 \%$ ) (Figure 2;

327 Table 2). Parallel differences between fishing periods were noticed for the $\mathrm{Z}$ by age (Table 2) 328 (with $\mathrm{p}[$ Fishing $]<0.002$, from Model A.2), and were consistently shown for both surveys 329 (with non-significant interactions of Fishing by Survey, $\mathrm{p}>0.6$ ).

330 Natural mortalities deduced from $\mathrm{Z}$ estimates by age during the fishing closure period

331 (proxies of M1 and M2+) were slightly affected by the omission of the 2005 and 2006 noisy 332 estimates and turned out to be $\mathrm{M} 1=0.66(\mathrm{CV}=11 \%)$ and $\mathrm{M} 2+=1.63(\mathrm{CV}=19 \%)$ (Table 2).

333 Such big difference in $\mathrm{Z}$ by age was consistently shown in both surveys (Figures 1 \& 2 and

334 Table 2) in the time series (Model A.1) and for the two fishing periods (Model A.2) (with $335 \mathrm{P}($ Old $)<0.0001$ and $\mathrm{p}\left(\right.$ Old ${ }^{*}$ Survey $)>0.2$ in both models $)$.

337 b) Natural mortality estimates from linear models (Model B) 
339 M estimates (intercepts) did not differ statistically between surveys, neither in the case of Z1+ $340(\mathrm{p}[$ Survey $]>0.6)$ nor by ages $\mathrm{Z} 1$ and $\mathrm{Z} 2+\left(\mathrm{p}[\right.$ Survey $]>0.3$ and $\mathrm{p}\left[O L D^{*}\right.$ Survey $\left.]>0.25\right)$ for any $341 \mathrm{RC}$ index or subset of data. Therefore the requisite for the joint analysis of the $\mathrm{Z}$ from both 342 surveys using this model was verified.

344 As regards total mortality $(\mathrm{Z1}+$ ), the two-slope model on RCSurvey2 (Figure 3) resulted in $345 \mathrm{M} 1+$ of $1.05(\mathrm{CV}=19 \%)$ (Table 3), though the slopes were not significantly different $346(\mathrm{p}=0.283)$. This estimate was very close to the mean of the individual $\mathrm{M} 1+$ estimates from the 347 surveys, which was $1.14(\mathrm{CV}=26 \%)$ for the DEPM and $0.953(\mathrm{CV}=26 \%)$ for the acoustic

348 (Table 3). Forcing a common slope for both surveys on RCSurvey2 made the single slope 349 model significant and resulted in a M1+ of about 1.15 (with a CV of 15\%). The RCJoint2 350 estimator results in a $\mathrm{M} 1+$ of $0.885(\mathrm{CV}=20 \%)$. Removal of the suspicious $\mathrm{Z} 1+$ values 351 corresponding to RCSurvey $2>0.8$ and Year $>2011$ globally improved the fitting while leading 352 to a reduction of M1+ estimates (Table 3 and Figure 3). In summary, if the complete dataset 353 pointed towards an M1+ range of between 0.88 and 1.15 , the analysis of the subset of data 354 reduced those values to a range between 0.78-0.92, with RCSurvey2 pointing towards higher 355 M1+ than RCJoint2.

357 Analysis of $\mathrm{Z}$ by ages ( $\mathrm{Z} 1$ and $\mathrm{Z2}+$ ) revealed significant differences in the intercepts (M) by 358 age $(\mathrm{P}[O l d]<0.001)$ for any $\mathrm{RC}$ index. In the case of RCSurvey2, the two-slope model 359 (Figure 4) pointed to $\mathrm{M} 1=0.94$ and $\mathrm{M} 2=1.79$, with $\mathrm{CVs}$ around $17 \%$ and $14 \%$, respectively 360 (Table 4). These estimates were close to the mean of individual survey estimates (Table 4) 361 but the slopes by survey were not significantly different $(p=0.437)$. The single slopes model 
362 became fully significant and resulted in very similar values. Using RCJoint2 (Table 4 and 363 Figure 4, bottom panels) resulted in slightly lower M1 (at $0.82, \mathrm{CV}=23 \%$ ) and rather similar $364 \mathrm{M} 2$ (at $1.73, \mathrm{CV}=17 \%$ ).

365 Working with the subset of data (Figure $4 \mathbf{b}$ and Table $4 \mathbf{b}$ ) improved the overall fittings and 366 again led to a reduction of $\mathrm{M}$ estimates. For the two-slope model on RCSurvey2, the values 367 decreased to 0.78 for $\mathrm{M} 1(\mathrm{CV}=25 \%)$ and to 1.46 for $\mathrm{M} 2+(\mathrm{CV}=20 \%)$, and achieved very 368 similar values in the single slope model. For the RCJoint2, the use of the subset of data 369 reduced $\mathrm{M} 1$ to $0.58(\mathrm{CV}=35 \%)$ and $\mathrm{M} 2$ to $1.57(\mathrm{CV}=19 \%)$. In summary, the complete dataset 370 resulted in M1 in the range $0.82-0.94$ and M2+ around 1.73 , whilst analysis restricted to the 371 subset of data reduced those estimates to M1 within the range $0.58-0.78$, and $\mathrm{M} 2+$ in the 372 range 1.40-1.57, with RCSurvey2 pointing towards higher M1 than RCJoint2.

374 C) Natural mortality estimates from integrated assessments

375 Optimization for a single overall natural mortality (M1+, common for all ages) including all 376 input data resulted in M values of around 1.15 and 1 for the WSSQ and LLHR optimizations, 377 respectively (Table 5a). In all cases, the response surface was rather flat around the optimum $378(+/-0.1)$, being basically guided by the age-structured survey indexes, followed by the catches 379 at age information and finally, to a lesser extent, by the biomass survey indexes - which in 380 fact favored slightly lower M1+ optimums (around 0.7-1.1) (Figure 5a). In all cases, the 381 small contribution of JUVENA favored M1+ values at or above the synthetic optimum. The 382 sensitivity of these results to the omission of the 2012 survey estimates was negligible, with 383 optimums differing by less than $1 \%$ (not shown for simplicity). 
385 Optimization of natural mortality by ages (M1 and M2+) for a Jan-Dec calendar year

386 suggested, for both objective functions, that the lower the M1 the better the fitting achieved,

387 though improvements gradually reduced, being minimal below 0.7 (Figure 5b) with optimum

388 M1 around 0.15-0.3 and M2+ around 1.35-1.45 (Table 5b). Applying a July-June calendar

389 year provided optimums for both objective functions of around 0.7 for M1 (Figure 5c and

390 Table 5c) and 1.4-1.5 for M2+ (see joint confidence intervals by models in Figure 6a\&b).

391 Results are basically guided by the age-structured survey indexes which provide a rather

392 parallel response, whilst all other inputs are non-informative (almost flat) (Figures 5b \& c).

393 Compared to the assessments assuming a single natural mortality $(\mathrm{M} 1+)$, the assessments

394 allowing $\mathrm{M}$ at age to be estimated (M1/M2+) get a better fitting (higher likelihood - Figure 6)

395 and lower Akaike's Information Criterion (Table 5). These results were insensitive to the

396 omission of the 2012 survey estimates (not shown).

397 The $\mathrm{M}$ at age estimates obtained by the integrated models for the July-June calendar year are

398 consistent with those produced by the direct and linear models previously reported (Figure 7).

400 D) Sensitivity to Ageing Errors

402 Inclusion of 5\% ageing errors did not affect the compatibility of $\mathrm{Z} 1+$ estimates by survey, 403 neither in the raw data analysis $(\mathrm{P}=0.97)$, nor in the log-linear models $(\mathrm{P}=0.71)$. This 404 compatibility also applied to the analysis of $\mathrm{Z}$ by age where all terms with Survey were not 405 significant either. Therefore the joint analysis of both surveys was again statistically 406 supported. 
408 Consideration of a 5\% ageing error raised up the M1+ estimates by about 0.14 in direct and 409 lineal model analyses, resulting for the subset of data all M1+ in the range of 0.94-1.08 410 (Table 2 and 3). Incorporation of this ageing error into the integrated models leads to minor 411 increases of the original M1+ estimates (by about 0.04 ), resulting in poorer fits and larger 412 AICc than for uncorrected data (Table 5).

413 By age, consideration of a 5\% ageing error meant that paired raw Z1 estimates were still on 414 average below those of Z2+ for both surveys over the whole period (Table $2 \mathbf{b}$ ) (paired t-test $415 \mathrm{p}=0.0295)$, and more intensively during the closure period $(\mathrm{p}=0.0146)$.

416 The correction for a 5\% ageing error reduces the differences of $\mathrm{M}$ between age by increasing 417 M1 estimates by about 0.2 and $0.3-0.4$ in the direct and lineal model analysis, respectively, 418 and by reducing M2+ by a lesser extent (by about $0.08-0.16$ ). Nevertheless, M1 remains 419 invariantly below M2+, even though statistical significance is sometimes lost (Table 3). Both 420 integrated models, when considering a 5\% ageing error, also obtained a reduction of the 421 differences of $\mathrm{M}$ by age by increasing M1 and reducing M2+, but to a larger extent for the 422 January to December calendar year. Nevertheless, M1 remains invariantly below M2+. 423 Certainly, the improvement in fitting achieved by allowing $M$ to change by age is reduced 424 when compared to no ageing errors, but the differences are still significant (even though only 425 at alpha 0.06 for the WSSQ) (Figure 6) and the Akaike's Information Criterion improves (is 426 reduced), therefore still endorsing the $\mathrm{M}$ by age models over the single M1+ models.

427 Figure $7 \mathrm{~b}$ shows the general consistency and overlapping of the $\mathrm{M}$ at age estimates for the 428 different methods tested before (Figure 7).

\section{Discussion}


432 Estimating natural mortality is one of the main challenges in stock assessment (Vetter 1988;

433 Hilborn and Walters 1992; Gislason et al. 2010), and in order to do it, availability of research

434 surveys is essential (Sinclair 2001; Sparholt et al. 2002; Zhao et al. 2003; Francis 2011). The

435 basic assumption of this paper was that the direct monitoring program running since 1987,

436 through two research surveys (23 DEPM and 18 Acoustic surveys) and the closure of the

437 fishery for 5 years should enable the overall level of natural mortality and its pattern by age to

438 be inferred for the Bay of Biscay anchovy. This was supported by the compatibility of the $\mathrm{Z}$

439 estimates from both surveys and because, in spite of the large variability inherent to the data,

$440 \mathrm{Z}$ differed significantly between the open and closed fishing periods, being lower during the

441 latter period and therefore indicative of the natural mortality rates. Moreover, mortality at

442 ages two and older ( $\mathrm{Z} 2+$ ) was significantly higher than at age one (Z1) throughout the time

443 series, suggesting an increasing pattern of natural mortality by age.

445 The series of $\mathrm{Z}$ estimates have a large inter-annual variability which must be linked either to 446 observation errors in the surveys or to variability in natural and fishing mortality, or both.

447 Observation errors in surveys are evidenced by the fluctuations in $\mathrm{Z}$ between consecutive 448 surveys (sometimes reaching negative values) and by the occasional strong divergences of 449 survey estimates (as in 2012). Variability of fishing mortality naturally happens for the 450 fisheries, which tend to stabilize catches when exploiting a highly fluctuating population (like 451 anchovy). Some variability of natural mortality has always been presumed and could be 452 linked to changes in the ecological environment (Vetter 1988; Zwolinski and Demer 2013).

453 For these reasons, we have chosen gradually improved estimators of natural mortality, 454 allowing for increasing data input and, in principle, greater noise filtering. 
456 The direct and linear models provide a natural mortality for all age groups (M1+) of between $457 \quad 0.81$ and 1.15 , which decreases to $0.78-0.92$ after filtering the suspected noise. The integrated 458 models indicate M1+ at about 1.15 for WSSQ and 1.00 for LLHR, i.e., at the upper range of 459 the estimates in the former models. Even though these estimates are not statistically different, 460 there can be several reasons explaining this preference for upper M1+ in the integrated 461 models. Firstly, their results include, in addition to the spring surveys, other auxiliary 462 information which partly favors this upper range of M1+ values, mainly by the recruitment 463 index and to a lesser extent the catches by age. Secondly, it should be pointed out that linear 464 models make inferences of M1+ from the decay between age groups $1+$ to $2+$, whilst 465 integrated models fit simultaneously the three age classes $(1 / 2 / 3+)$ with the same $\mathrm{M} 1+$, and as 466 such the former estimates may be closer to the weighted mean of $\mathrm{M}$ by age (according to their 467 abundance), while the latter is closer to an arithmetic mean (as residuals by age have equal 468 weights). Hence, weighted M1+ to age class abundance should favor the M1+ at the lower 469 range pointed out before, because M1 is lower, and will serve to better describe the average 470 change of the whole population. In any case, this results in a most likely range going from 4710.78 (RCJoint2) to 1 (log-likelihood assessment), which corresponds with an annual survival 472 of between $46 \%$ and $37 \%$. If a single figure is needed, a rough compromise could be in the 473 middle of the ranges, close to 0.9 for M1+ (annual survival rate of $41 \%$ ).

474 These results point towards a lower M1+ than the currently assumed value of 1.2 , which was 475 calculated in the 1990s on the basis of the DEPM survey alone (Uriarte et al. 1996; Prouzet et 476 al. 1999). Moving to an M1+ of 0.9 would imply a reduction of the average historical 477 estimates of SSB by about 30-35\%, and an inverse parallel increase of fishing mortality 478 estimates. 
479 This average natural mortality for adult anchovy in the Bay of Biscay is just slightly below 480 the values of 1.08 and 1.34 which result from applying Hoening's equation (1983) (for a 481 Tmax of 4) and that of Pauly (1980) (for von Bertalanffy growth parameters Linf, K and t0 482 about $18.05 \mathrm{~cm}, 0.77$ and 0.72 , respectively, as fitted to DEPM survey observations and a 483 mean temperature of $16^{\circ} \mathrm{C}$ ). Nevertheless, these $\mathrm{M} 1+$ estimates are rather similar to, albeit 484 slightly higher than, the ones reported for short-lived species of similar growth, such as sprats, 485 some Sardinops or Engraulidae (Beverton 1963, 1992; MacCall 1973; Methot 1989; Iversen 486 et al. 1993; Sinovčić 2000), but at a lower level than the ones reported for Peruvian anchovy 487 (Pauly et al. 1987), Anchoa mitchilli (Neweberger and Houde 1995) and other Engraulidae of 488 smaller maximum sizes (Bayliff 1967).

490 All the analyses improved by allowing $M$ to change with age: the Old factor was retained in 491 the linear models and the likelihood of the integrated models improved significantly when M 492 was estimated by age compared to the single common M1+ modeling (Figure 6). This led to 493 the conclusion that M1 was significantly lower than M2+ (Figure 7): On the one hand, the 494 direct $\mathrm{Z}$ estimate and the linear models resulted in a range of M1 from 0.45 to 0.94 when 495 using the full dataset, and a narrower range of about $0.6-0.8$ with the most reliable subset of 496 data. This corresponds with an annual survival of about $55 \%-45 \%$ for the 1 -year-old group. 497 On the other hand, M2+ was consistently about twice the value of M1: 1.59 to 1.79 for M2+ 498 with the full dataset and 1.4-1.65 for the most reliable subset of data. This corresponds with 499 an annual survival rate of about $25 \%-19 \%$ for ages two and older.

500 Furthermore, integrated assessment indicated $\mathrm{M}$ at age consistent with the former results, but 501 only for the July-June calendar, whilst the Jan-Dec calendar year suggested a better fit at a 502 lower M1 (Figure 7). For the latter modeling, such discrepancy arises from the pronounced 
503 mismatch between the calendar of application of natural mortality by age (January to

504 December) and the calendar between survey observations (from May to May) which have to

505 be fitted. Both integrated assessments from July to June (WSSQ and LLHR) produced almost

506 identical estimates as those from the linear models in RCSurvey2 on the most reliable subset

507 of data. This means that the population modeling context of the integrated assessment,

508 including other auxiliary information, has enabled natural filtering of much of the noise

509 affecting the individual spring survey estimates. In summary, both July-June integrated

510 assessments have captured the pattern of natural mortality at age between survey observations

511 (from May to May) well and are consistent with the former simpler linear models (particularly

512 with those using the reliable subset of data) (Figure 7). Simplifying, they all pointed towards

513 an M1 of around 0.70 and M2+ of around 1.40 (i.e. survivals about $50 \%$ and $25 \%$

514 respectively).

515 Our data do not allow saying when this additional mortality at age 2 and older happens during

516 the year; however the sharp decrease of the 2 and 3 year-olds is already noticeable in the

517 fishery after spawning, during the second half of the year (ICES 2005, 2013; Uriarte et al.

518 1996). This could have been the result of some permanent emigration of the old (2+) fishes

519 outside of the major fishing grounds, off the Bay of Biscay, but such a possibility has never

520 been proven and it is well known that, every spring, old fishes concentrate again to spawn in

521 the southeast of the Bay of Biscay (Motos et al. 1996) where the surveys take place.

522 Therefore, this increasing mortality at age 2 and older is most likely due to either increased

523 vulnerability to predation at older ages or to natural biological mortality, probably reflecting

524 senescence of anchovies at age 2 and older. No major concentration of predators on adults in

525 early summer has been reported. The Bay of Biscay is an area of bottom-up controlling of the

526 upper trophic levels (Lassalle et al. 2011), with anchovy being one (and not the main) among

527 several small pelagic and other fishes (such as sardine, sprat, horse mackerel, blue whiting, 
528 etc) connecting the plankton communities to piscivorous species (Sanchez and Olaso 2004;

529 Preciado et al. 2008). It contributes to the diets of demersal species such as hake, monkfish,

530 megrim and tunnidae but mainly as juveniles (Guichet 1995; Preciado et al. 2008; Lezama-

531 Ochoa et al. 2010; Goñi et al. 2011, 2012; López-López et al. 2012), whilst in adult anchovy

532 it seems that some demersal fishes (John dory and hake, etc) and cetaceans prey routinely all

533 year around (Preciado et al. 2008; Mahe et al. 2007; Lassalle et al. 2012; Meynier et al.

534 2008). Therefore, by discarding any ecological higher predation on adults, we tend to think

535 that senescence might be occurring at the age of two and older, in accordance with the

536 expectation of observable senescent mortality affecting short-lived cupleoids (Beverton 537 1963).

539 We hypothesized that this anchovy population may suffer from "reproductive stress" inducing

540 increased mortality, particularly after its second spawning event. It is known that the large

541 energy cost of reproduction can induce some varying rates of mortality due to "reproductive

542 stress", as shown for cod (Hutchings 2005), or in extreme cases, of semelparous species like

543 Pacific salmon Oncorhynchus, which reproduces and dies, whereby dramatic hormonal

544 changes induce starvation that causes intestine deterioration by necrosis and inflammatory

545 processes during spawning migration (McBride et al. 1986). Examples of mortality associated

546 to reproductive stress in short-lived species are common, as in invertebrates (squids and

547 shrimps - Caddy et al. 1996) and fishes such as Aphia minuta (an extremely short-lived goby

548 where apoptosis of enterocytes is related to post spawning mortality - Caputo et al. 2002),

549 capelin Mallotus villosus (Vilhjálmsson 1992; Gjøsæter 1998) and in the short-lived gadoid

550 Norway pout (Nielsen et al. 2012). Anchovy in the Bay of Biscay invests much energy in

551 reproduction having one of the highest spawning frequencies among the Engraulidae, capable

552 of increasing slightly with size and age (Uriarte et al. 2012), which results in a very high daily 
553 fecundity (Santos et al. in press). Many of the 1-year-old fishes lay down a spawning check at 554 the end of the spawning season (in early summer) (Petitgas and Grelier 2003; Uriarte et al. 5552002 , in press) being probably indicative of the limiting condition of many anchovies after 556 spawning (Pecquerie et al. 2012). While they have reached about $88 \%$ of their maximum 557 attainable growth $(18.3 \mathrm{~cm})$ by the age of 2 , spawning starts earlier and probably lasts longer 558 than at age 1, with a likely increase in the number of batch-spawning events during the 559 spawning season (Motos et al. 1996; Motos 1996; Pecquerie et al. 2009), in accordance with 560 the indications for other Engraulidae (Parrish et al. 1986; Claramunt et al.2007; Cubillos and 561 Claramunt 2009). On average, 2-year-old anchovies do not resume opaque edge formation in 562 otoliths until mid-June, beyond the mid-point of the spawning season (Uriarte et al. 2002, in 563 press), this being also indicative that much of the energy of this age group is invested in 564 reproduction during the first half of the year. This reproductive strategy of anchovy may 565 result in some physiological reproductive stress at the end of the spawning season for the age $5662+$ group, which may explain the increase in natural mortality observed in our analysis. As 567 such, this population of anchovies may have evolved in its fluctuating environment by 568 allowing some non-negligible chances of reproducing over two spawning seasons before 569 senescence. This would enhance the opportunities to overcome single (not repeated) 570 environmentally-induced failures of recruitment. This strategy would place anchovy among 571 capelin, which mostly dies after its first spawning (Vilhjálmsson 1992; Gjøsæter 1998), and 572 sprats, sardines or sandeels which have progressively longer adult life expectation with 573 several annual reproductive cycles (Cook 1994; Nunes et al. 2011; Zwolinski and Demer 574 2013); ending up with the herrings, which seem to have up to eight reproductive seasons 575 during their life history before increased mortality by senesce shows up (as for Norwegian 576 spring-spawning herring - Beverton et al. 2004). To our knowledge, senescence in 577 Engraulidae had only been suggested previously for Northern anchovy (from age 2 and older 
578 - MacCall 1973 - based on analysis of catch ratio from catches and surveys) and for the

579 anchovy in the Yellow Sea (from age 3 and older - Zhao et al. 2003 - based on analysis of

580 surveys). We suspect that this pattern of increasing mortality by age may be applicable to

581 other Engraulidae, whereby assessments following the usual constant mortality assumption

582 often results in non-understandable big changes in catchability by age in surveys (Giannoulaki

583 et al. 2014).

584 In terms of assessment, the new $M$ estimates would impact the average level of spawning

585 biomass approximately in proportion to the reduction in average M. For instance, for LLHR

586 modeling, moving from the single M1+ hypothesis at 1.2 to its optimum at 1.00 would reduce

587 mean biomass by about $27 \%$, while moving further from the optimum $\mathrm{M} 1+$ to its optimal

588 mortality by age would result in a minor reduction of about $5 \%$. So once M1+ is set at its

589 optimum, a further change to the optimum $\mathrm{M}$ by age does not imply additional major changes

590 to mean biomass estimates. In spite of this, however, this latter change to $\mathrm{M}$ by age will

591 probably have implications in any population and fishery projections which might be required

592 for the provision of advice to managers. For instance, for this anchovy old populations

593 (composed mainly of ages 2+) will decay faster (with $M$ around 1.4) than young ones

594 (composed mainly of age 1) (with an M around 0.7-0.8). Therefore, in terms of management

595 moving to unbiased $\mathrm{M}$ estimates should also improve the quality of advice as reported for

596 other species (Lee et al. 2011; Zwolinski et al. 2013). Certainly, the perception of fishing

597 mortality will change inversely to the estimation of biomass levels. Furthermore, as the new

598 M estimates change the perception of cohort dynamics in mass, this will affect the estimation

599 of management-related reference points $\left(\mathrm{F}_{0.1}, \mathrm{~F}_{\mathrm{MSY}}\right.$, etc. $)$. 
601 These results are partly sensitive to the maximum level of ageing errors put into 602 consideration. Correction of such a 5\% ageing error moved the direct and linear model 603 estimates of M1+ and of M1 upwards, while slightly reducing M2+. This was associated with 604 a partial loss of the statistical significance of the difference between M1 and M2+ (Figure 7b). 605 Integrated models were less affected in the M1+ estimates (remaining just slightly above the 606 original optimums), and also showed a reduction of the differences between M1 and M2+ 607 (Table 5). Nevertheless, integrated assessments show that models allowing $M$ by age 608 estimates achieve better fittings than single M1+ models (with $\mathrm{p}<0.056$ for the WSSQ and $609 \mathrm{p}<0.000$ for the LLHR) (Figure 6). Therefore, even after consideration of this maximum level 610 of potential ageing errors, the significant increase pattern of natural mortality at age is still 611 supported by integrated assessments. In any case, $\mathrm{M}$ estimates will be conditioned by the 612 actual level of ageing errors affecting the observations.

614 Certainly, the results depend upon the assumption of the constant catchability of surveys 615 across ages, on which $\mathrm{Z}$ estimates rely (an assumption we have proved to be compatible with 616 the data). Sustaining this is not true would be difficult to understand, given the good spatial 617 coverage of the surveys, and would imply that the prevailing null hypothesis should be on the 618 assumption that $\mathrm{M}$ is equal across ages. Biologically, this is known not to be true (Vetter 619 1988), even though for simplification this has been the null hypothesis for the assessment of 620 the exploited range of ages of most of the long and short-lived fish resources. Although this 621 has already been questioned and revised for younger ages (Caddy 1991; Abella et al. 1997; 622 Gislason et al. 2010), it has not been sufficiently revised yet for the inclusion of senescence in 623 the older age classes. And, certainly for short-lived species, senescence should have been 624 presumed to be noticeable not too long after reaching maturity (Beverton 1963). By accepting 625 that the null hypothesis should be that senescence is present, then our analysis shows 
626 consistency of the observations with the hypothesis, and we would rely more on the

627 observations of the age structures reported by surveys rather than on doubtful assumptions of

628 constant natural mortality across ages; and finally the assessment can become parsimonious

629 (as in our case with two surveys) in terms of demanding a lesser amount of parameters to

630 infer population size (i.e. lesser amount of catchability at age parameters in comparison to the

631 increased number of natural mortality by age).

632

633 A correct selection of the natural mortality serves to properly scale the assessments around

634 true population abundance values and this becomes particularly relevant in the context of

635 relative indexes of population abundance, and even more for short-lived species. In this paper

636 we have shown that that the overall natural mortality M1+ was somewhat below what had

637 been assumed so far, and furthermore, that natural mortality at ages $2+$ is higher than at age 1,

638 in line with expectation of senescence. In achieving this conclusion, the continuous

639 monitoring of the population by two parallel and independent methods for many years,

640 including a period of fishing closure, has been essential, as it has provided sufficient contrast

641 for the analysis. The natural mortality issue should be revisited periodically when additional

642 years of survey observations and improvements in our base knowledge become available.

643 Relevant improvements may come from better understanding of survey catchability, or of the

644 accuracy of age determinations for this anchovy, besides, for instance, from monitoring

645 biological and biochemical markers of aging and reproductive stress or from further studies

646 on eco-trophic interactions.

648 Acknowledgements: The surveys for the monitoring of the anchovy fishery have been

649 supported by national funds from France and Spain (including the autonomous government of 
650 the Basque Country) and by the EU Data Collection Regulation (through national programs).

651 Pablo Abaunza, Unai Cotano, Eneko Bachiller, Nicolás Goñi, Maite Louzao, Francisco

652 Velasco and Izaskun Preciado are thanked for comments and discussion on some parts of the

653 paper. Finally we wish to thank two anonymous referees for their valuable suggestions and

654 comments which largely improved the paper. This paper is contribution $\mathrm{n}^{\circ} 741$ from AZTI

655 (Marine Research).

656

657 REFERENCES:

658

659 Beverton, R.J.H. 1963. Maturation, growth, and mortality of clupeid and engraulid stocks in 660 relation to fishing. Rapp. p.-v. réun. - Cons. int. explor. Mer. 154 : 44-67.

661

662 Beverton, R.J.H. 1992. Patterns of reproductive strategy parameters in some marine teleost 663 fishes. J. Fish Biol. 41(Suppl. B): 137-160.

664

665 Beverton, R.J.H., Hylen, A., Østvedt, O.-J., Alvsvaag, J. and Iles, T.C. 2004. Growth, 666 maturation, and longevity of maturation cohorts of Norwegian spring-spawning herring. ICES 667 J. Mar. Sci. 61: 165-175.

668

669 Boyra G., Martinez, U., Cotano, U., Santos, M., Irigoien, X., and Uriarte, A. 2013: Acoustic

670 surveys for juvenile anchovy in the Bay of Biscay: abundance estimate as an indicator of the 
671 next year's recruitment and spatial distribution patterns. ICES J. Mar. Sci. 70: 1354-1368.

672 doi:10.1093/icesjms/fst096

673

674 Caddy, J.F. 1991. Death rates and time intervals: is there an alternative to the constant natural 675 mortality axiom? Rev. Fish. Biol. Fish. 1: 109-138.

676

677 Caddy, J.F. 1996. Modelling natural mortality with age in short-lived invertebrate 678 populations: definition of a strategy of gnomonic time division. Aquat. Living Res. 9: 197679207.

680

681 Caputo, V., Candi, G., Arneri, E., Mesa, M. L., Cinti, C., Provinciali, M., Cerioni, P. N., et al. 682 2002. Short lifespan and apoptosis in Aphia minuta. J. Fish Biol. 60: 775-779.

683

684 Charnov, E.L., Turner, T.F., and Winemiller, K.O. 2001. Reproductive constraints and the 685 evolution of life histories with indeterminate growth. Proc. Natl. Acad. Sci. U.S.A. 98:94606869464.

687

688 Charnov, E.L., and Gillooly J.F. 2004. Size and Temperature in the Evolution of Fish life 689 Histories. Integr. Comp. Biol. 44: 494-497 
691 Chen S. and Watanabe, S. 1989. Age dependence of Natural Mortality coefficient in Fish 692 Population Dynamics. Nippon Suisan Gakkaishi. 55(2): 205-208.

693

694 Claramunt, G., Serra, R., Castro, L.R., and Cubillos, L.A. 2007. Is the spawning frequency 695 dependent on female size? Empirical evidence in Sardinops sagax and Engraulis ringens off

696 northern Chile. Fish. Res. 85: 248-257.

697

698 Cook R.M. 2004. Estimation of the age-specific rate of natural mortality for Shetland 699 sandeels. ICES J. Mar. Sci. 61: 159-169.

700

701 Cotter A.J.R., Burst, L., Paxton, C.G.M., Fernandez, C., Buckland S.T., and Pan, J-X. 2004.

702 Are stock assessment methods too complicated? Fish Fish. 5: 235-254.

703

704 Cubillos, L., and Claramunt, G. 2009. Length-structured analysis of the reproductive sea-son

705 of anchovy and common sardine off central southern Chile. Mar. Biol. 156:1673-1680.

706

707 Francis, R.I.C.C. 2011. Data weighting in statistical fisheries stock assessment models. Can.

708 J. Fish. Aquat. Sci. 68: 1124-1138.

709

710 Giannoulaki M., Ibaibarriaga L., Antonakakis K., Uriarte A., Machias A., Somarakis S,

711 Sanchez S., and Roel B. 2014. Applying a two-stage Bayesian dynamic model to a short-lived 
712 species, the anchovy, in the Aegean Sea (Eastern Mediterranean). Comparison with an

713 Integrated Catch at Age stock assessment model. Medit. Mar. Sci. 15 (2): 350-365

714

715 Gislason H., Daan, N., Rice, J.C., and Pope, J.G. 2010. Size, growth, temperature and the

716 natural mortality of marine fish. Fish Fish. 11: 149-158.

717

718 Gislason, H., Pope, J.G., Rice, J.C. and Daan, N. 2008. Coexistence in North Sea fish

719 communities: implications for growth and natural mortality. ICES J. Mar. Sci. 65: 514-530.

720

721 Gjøsæter, H. 1998. The population biology and exploitation of capelin (Mallotus villosus) in 722 the Barents Sea. Sarsia 83:453-496.

723

724 Golubev, A. 2009. How could the Gompertz-Makeham law evolve. J. Theor. Biol. 258: 1-17.

726 Goñi N, Logan J, Arrizabalaga H, Jarry M, and Lutcavage M. 2011. Variability of albacore

727 (Thunnus alalunga) diet in the Northeast Atlantic and Mediterranean Sea. Mar. Biol. 158(5):

$728 \quad 1057-1073$

730 Goñi N, Peninon V, Arrizabalaga H, and Uriarte A. 2012. Spatial and temporal variation of

731 anchovy predation by albacore and bluefin tuna in the Bay of Biscay ICES CM 2012/I:04 
733 Gulland J.A. 1983. Fish Stock Assessment: A manual of basic methods. FAO/ Willey series

734 on food and agriculture; v.1. John Willey and Sons, New York.

735

736 Guichet R. 1995. The diet of European hake (Merluccius merluccious) in the northern part of

737 the Bay of Biscay. ICES J. Mar. Sci. 52: 21-31

738

739 Hoenig, J. M. 1983. Empirical use of longevity data to estimate mortality rates. Fish. Bull.

740 81(4):898-903.

742 Hewit D. and Hoening J. M. 2004. Comparison of two approaches for estimating natural

743 mortality based on longevity. Fish. Bull. 103(2): 433-437

745 Hilborn, R., and Walters, C.J. 1992. Quantitative Fisheries Stock Assessment: Choice, 746 Dynamics and Uncertainty. Chapman and Hall, New York.

748 Hutchings, J.A. 2005. Life history consequences of overexploitation to population recovery in

749 Northwest Atlantic cod (Gadus morhua). Can. J. Fish. Aquat. Sci. 62: 824-832.

751 Ibaibarriaga, L., Fernandez, C., Uriarte, A and Roel, B.A. 2008. A two-stage biomass 752 dynamic model for the Bay of Biscay anchovy: A Bayesian Approach. ICES J. Mar. Sci. 65: $753191-205$. 
755 ICES. 2005. Report of the Working Group on the Assessment of Mackerel, Horse Mackerel, 756 Sardine and Anchovy (WGMHSA), 6 - 15 September 2005, Vigo, Spain. ICES C.M. 757 2006/ACFM:08

758

759 ICES. 2013. Report of the Working Group on Southern Horse Mackerel, Anchovy and 760 Sardine (WGHANSA), 21 - 26 June 2013, Bilbao, Spain. ICES CM 2013/ACOM:16.

762 Iversen, S.A., Zhu D., Johannessen, A., and Toresen, R. 1993. Stock size, distribution and 763 biology of anchovy in the Yellow Sea and East China. Sea. Fish. Res. 16: 147-163.

765 Jorgensen C., and Holt, R.E., 2013. Natural mortality: Its ecology, how it shapes fish life 766 histories, and why it may be increased by fishing. J. Sea Res. 75: $8-18$

768 Lassalle, G., Lobry, J., Le Loc'h, F., Bustamante, P., Certain, G., Delmas, D., Dupuy, C., et 769 al. 2011. Lower trophic levels and detrital biomass control the Bay of Biscay continental shelf 770 food web: implications for ecosystem management. Progress in Oceanography. 91: 61-75.

772 Lassalle, G., Gascuel, D., Le Loc'h, F., Lobry, J., Pierce, G. J., Ridoux, V., Santos, M. B., 773 Spitz, J., and Niquil, N. 2012. An ecosystem approach for the assessment of fisheries impacts 774 on marine top predators: the Bay of Biscay case study. ICES J. Mar. Sci. 69: 925-938. 
778 Biscay. Progress in Oceanography. 86: 105-114.

Lee, H.-H., Maunder, M.N., Piner, K.R., Methot R.D., 2011. Estimating natural mortality

781 within a fisheries stock assessment model: an evaluation using simulation analysis based on 782 twelve stock assessments. Fish. Res. 109: 89-94.

784 López- López, L., Preciado, I., Villamor, B., Velasco, F., Iglesias, M., Nogueira, E., 785 Gutierrez-Zabala, J.L., and Olaso, I. 2012. Is juvenile anchovy a feeding resource for the 786 demersal community in the Bay of Biscay? On the availability of pelagic prey to demersal 787 predators. ICES J. Mar. Sci. 69: 1394-1402.

789 Lorenzen, K. 1996. The relationship between body weight and natural mortality in juvenile 790 and adult fish: a comparison of natural ecosystems and aquaculture. J. Fish Biol. 49: 627-647. 
796 Massé, J. 1996. Acoustic observations in the Bay of Biscay: schooling, vertical distribution,

797 species assemblages and behaviour. Sci. Mar. 60: 227-234.

798

799 Massé et al., in press: Spring Acoustic Surveys. Pelgas survey. In Pelagic Surveys series for

800 sardine and anchovy in ICES Areas VIII and IX (WGACEGG) - Towards an ecosystem

801 approach. Edited by J. Massé, A. Uriarte, M. M. Angelico, P. Carrera. ICES CCR

802 (Cooperative Research Report). Denmark.

803

804 MacCall A. 1973. The mortality rate of Engraulis mordax in southern California. Calif. Coop.

805 Oceanic Fish. Invest. Rep. Vol XVII: 131-135

806

807 McBride, J. R., Fagerlund, U. H. M., Dye, H. M. and Bagshaw, J. 1986. Changes in structure

808 of tissues and in plasma cortisol during the spawning migration of pink salmon,

809 Oncorhynchus gorbuscha (Walbaum). J. Fish Biol. 29: 153-166.

810

811 Methot R.D., and Wetzel, C.R. 2013. Stock synthesis: A biological and statistical framework

812 for fish stock assessment and fishery management. Fish. Res. 142: 86- 99.

813

814 Meynier, L., Pusineri, C., Spitz, J., Santos, M.B., Pierce, G.J., and Ridoux, V. 2008.

815 Intraspecific dietary variation in the short-beaked common dolphin (Delphinus delphis) in the

816 Bay of Biscay: importance of fat fish. Mar. Ecol. Pr. Ser. 354: 277-287. 
818 Motos, L. 1996. Reproductive biology and fecundity of the Bay of Biscay anchovy population 819 (Engraulis encrasicolus L.). Sci. Mar. 60 (Suppl. 2) 195-207.

821 Motos, L., Uriarte, A., Valencia, V. 1996. The spawning environment of the Bay of Biscay 822 anchovy (Engraulis encrasicolus L.). Sci. Mar. 60 (Suppl. 2), 117-140.

824 Motos, L., Uriarte, A., Prouzet, P., Santos, M., Alvarez, P., and Sagarminaga, Y. 2005. 825 Assessing the Bay of Biscay anchovy population by DEPM: a review 1989-2001. In Report 826 of the SPACC Meeting on Small Pelagic Fish Spawning Habitat Dynamics and the Daily Egg 827 Production Method (DEPM). Edited by L.R. Castro, P. Freón, C. D. van der Lingen and A. 828 Uriarte. GLOBEC Report 22, xiv, pp. 88-90.

830 Nielsen, J.R., Lambert, G., Bastardie, F., Sparholt, H., and Vinther, M. 2012. Do Norway pout 831 (Trisopterus esmarkii) die from spawning stress? Mortality of Norway pout in relation to 832 growth, sexual maturity, and density in the North Sea, Skagerrak, and Kattegat. ICES J. Mar. 833 Sci. 69: 197-207.

835 Newberger, T.A., and Houde E.D. 1995 Population biology of bay anchovy Anchoa mitchilli 836 in the mid Cheasapeake Bay. Mar. Ecol. Pr. Ser. 116: 25-37. 
838 Nunes, C., Silva, A., Marques, V., Ganias, K. 2011. Integrating fish size, condition, and 839 population demography in the estimation of Atlantic sardine annual fecundity. Ciencias 840 Marinas 37(4B): 565-584

841

842 Parrish, R.H., Mallicoate, D.L. and Klingbeil, R.A. 1986. Age dependent fecundity, number 843 of spawnings per year, sex ratio, and maturation stages in northern anchovy, Engraulis 844 mordax. Fish. Bull. 84: 503-517.

846 Patterson K.R. and Melvin, G.D. 1996. Integrated Catch at age Analysis. Version 1.2. Scottish 847 Fisheries Research Report No. 58. FRS: Aberdeen.

849 Pauly, D. 1980. On the interrelationships between natural mortality, growth parameters, and 850 mean environmental temperature, in 175 fish stocks. J. Cons. Perm. Int. Explor. Mer 39: 175851192.

853 Pauly, D., Palomares, M.L., Gayanilo, F.C. 1987. VPA estimates of the monthly population 854 length composition, recruitment, mortality, biomass and related statistics of Peruvian 855 anchoveta 1955-1981. In The Peruvian Anchoveta and its Upwelling Ecosystem: Three 856 Decades of Change. Edited by D. Pauly, and I. Tsukayama. ICLARM Studies and Reviews 857 15, Instituto del Mar del Perú (IMARPE), Callao, Perú; Deutsche Gesellschaft fur Technische 858 Zusammenarbeit (GTZ), Eschborn. Federal Republic of Germany; and International Center 859 for Living Aquatic Resources Management (ICLARM), Manila, Philippines, pp. 142-166. 
861 Pecquerie L., Petitgas, P., and Kooijman, S.A.L.M. 2009. Modeling fish growth and 862 reproduction in the context of the Dynamic Energy Budget theory to predict environmental 863 impact on anchovy spawning duration. J. Sea Res. 62: 93-105

864

865 Petitgas, P and Grellier, P. 2003. Size selective processes for anchovy in Biscay, 2000-2002:

866 recruitment, adult survival and spawning. ICES CM2003/N:07. 11 pp.

867

868 Petitgas, P., Uriarte, A., Nogueira, E., Massé, J., and Cotano, U. 2010. Bay of Biscay 869 anchovy. In Life cycle spatial patterns of small pelagic fish in the Northeast Atlantic. Edited 870 by P. Petitgas. ICES Coop. Res. Rep. 306 (93pp): pp.40-44

872 Preciado, I., Velasco, F., and Olaso, I. 2008. The role of pelagic fish as forage for the 873 demersal fish community in the Southern Bay of Biscay. J. Mar. Syst.72: 407-417.

875 Prouzet, P., Uriarte, A., Villamor, B., Artzruoni, M., Gavrart, O., Albert, E., et Biritxinaga, E. 876 1999: Estimations de la mortalité par pêche $(\mathrm{F})$ et naturelle $(\mathrm{M})$ à partir des méthodes directes 877 d'évaluation de l'abondance chez les petits pélagiques. Précision des estimateurs. Rapport 878 final du contract européen 95/PRO/018. 
880 Quinn, T.J., and Deriso, R.B. 1999. Quantitative Fish Dynamics. Oxford University Press, 881 New York.

882

883 Reznick, D.N., Ghalambor, C.K., and Nunney, L. 2002. The evolution of senescence in fish.

884 Mech. Age. Dev.123: 773-789.

885

886 Reznick, D., Bryant, M., and Holmes, D. 2006. The evolution of senescence and post-

887 reproductive lifespan in guppies (Poecilia reticulate). PLoS Biology, 4(1) e7: 136-143.

888

889 Sanchez, F., and Olaso, I., 2004. Effects of fisheries on the Cantabrian Sea shelf ecosystem.

890 Ecol. Mod. 172: 151-174.

891

892 Santos M., Uriarte, A., Boyra G., and Ibaibarriaga L., in press. Anchovy DEPM surveys 2003

893 - 2012 in the Bay of Biscay (subarea VIII) BIOMAN. In Pelagic Surveys series for sardine

894 and anchovy in ICES Areas VIII and IX (WGACEGG) - Towards an ecosystem approach.

895 Edited by J. Massé, A. Uriarte, M. M. Angelico, P. Carrera. ICES CCR (Cooperative

896 Research Report). Denmark.

897

898 Santos, M., Uriarte, A., Ibaibarriaga, L. 2011. Spawning Stock Biomass estimates of the Bay 899 of Biscay anchovy (Engraulis encrasicolus, L.) in 2010 applying the Daily Egg Production 900 Method. Rev. Invest. Mar. 18(5): 76-90. 
902 Sinclair, A.F. 2001. Natural mortality of cod (Gadus morhua) in the southern Gulf of St.

903 Lawrence. ICES J. Mar. Sci. 58: 1-10.

905 Somarakis, S., Palomera, I., Garcia, A., Quintanilla, L., Koutsikopoulos, C., Uriarte A., and 906 Motos, L. 2004. Daily egg production of anchovy in European waters. ICES J. Mar. Sci. 61: $907 \quad 944-958$

908 Sparholt, H., Larsen, L. I., and Nielsen, J. R. 2002. Non-predation natural mortality of

909 Norway pout (Trisopterus esmarkii) in the North Sea. ICES J. Mar. Sci. 59: 1276-1284.

911 Tanasichuk, R.W. 2000. Age-specific natural mortality rates of adult Pacific herring (Clupea

912 pallasi) from southern British Columbia. Can. J. Fish. Aquat. Sci. 57: 2258-2272

914 Terzibasi, E., Valenzano, D.R., and Cellerino, A. 2007. The short-lived fish Nothobranchius

915 furzeri as a new model system ageing studies. Exp. Gerontol. 42: 81-89.

916

917 Uriarte, A., Blanco, M., Cendrero, O., Grellier, P., Millán, M., Morais, A., Rico, I. 2002.

918 Report of the Workshop on anchovy otoliths from subarea VIII and division Ixa (Annex to

919 PELASSES report EU study Project -EC DG XIV Contract nº99/010 and Working Document

920 to the ICES Working Group on the assessment of Mackerel, Horse Mackerel, Sardine and

921 Anchovy. Copenhagen, 10-19 September 2002. (ICES Repository, available from

922 http://www.ices.dk/community/Documents/PGCCDBS/) [accessed 16 February 2015] 
924 Uriarte, A., Prouzet, P., Villamor, B. 1996. Bay of Biscay and Ibero Atlantic anchovy

925 populations and their fisheries. Sci. Mar. 60 (Supl.2): 237-255

926

927 Uriarte A., Alday A., Santos M, and Motos L. 2012. A re-evaluation of the spawning fraction

928 estimation procedures for Bay of Biscay anchovy, a species with short interspawning

929 intervals. Fish. Res. 117-118: 96-111. doi:10.1016/ j.fishres.2011.03.002

930

931 Uriarte, A., Rico, I., Villamor, B., Duhamel, E., Dueñas, C., Aldanondo, N., and Cotano, U.,

932 in press. Validation of age determination using otoliths of the European anchovy (Engraulis

933 encrasicolus L.) in the Bay of Biscay. Mar. Freshwater Res.

934

935 Vetter, E.E. 1988. estimation of natural mortality in fish stocks: a review. Fish. Bull. 86(1):

$936 \quad 25-43$.

937

938 Vilhjálmsson, H. 2002. Capelin (Mallotus villosus) in the Iceland-East Greenland-Jan Mayen

939 ecosystem. - ICES Journal of Marine Science. 59: 870-883.

941 Wang Y., Liu, Q., Yu C., and Lian L. 2009. Estimation of instantaneous rate of natural

942 mortality from catch-at-age data and an abundance index based on extended survivors

943 method. Fish. Res. 97. 127-133. 
945 Williams, P.D., Day, T., Fletcher Q., and Rowe, L. 2006. The shaping of senescence in the

946 wild. Trends Ecol. Evol. 21 (8): 458-463. doi:10.1016/j.tree.2006.05.008

947

948 Woodhead, A.D. 1998. Aging, the fishy side: an appreciation of Alex Comfort's studies. Exp.

949 Gerontol. 33: 39-51.

950

951 Zhao, X., Hamre, J., Li, F., Jin, X., and Tang, Q. 2003. Recruitment, sustainable yield and

952 possible ecological consequences of the sharp decline of the anchovy (Engraulis japonicus)

953 stock in the Yellow Sea in the 1990s. Fish. Oceanogr. 12(4/5): 495-501.

954

955 Zwolinski, J. P., and Demer, D. A. 2013. Measurements of natural mortality for Pacific

956 sardine (Sardinops sagax). - ICES J. Mar. Sci. 70: 1408-1415. doi:10.1093/icesjms/fst110. 


\section{List of Tables}

Table 1: Matrix of age determination errors

Table 2: Mean $\mathrm{Z}$ estimates for $\mathrm{Z1+}, \mathrm{Z1}$ and $\mathrm{Z2}+$ by fishing periods and surveys or jointly for the two surveys (pooled surveys), for the raw data (a- upper tables) and assuming a 5\% ageing error (bbottom tables). The fishery was closed between July 2005 (with only very small catches in 2006) and December 2009.

Table 3: : Summary results from linear models on overall mortality $(\mathrm{Z1}+)$ and estimates of overall natural mortality (M1+) from the intercept of the linear models. a) Upper panel analysis for all data, b) bottom panel analysis for data with $\mathrm{RC}<0.8$ and year $<2011$. Left two columns estimates by surveys, central three columns pooled surveys estimates by RC indicators, and final three columns pooled surveys estimates for cases assuming $5 \%$ ageing errors. Values in red and italics with an asterisk are statistically not significant (with $p>0.05$ ).

Table 4: Summary results from linear models on estimates of $Z$ by age (from Age 1 to 2 and from Age $2+$ to $3+$ ), with estimates of M1 and M2+ from the intercepts of the fitted models. a) Upper panel analysis for all data, b) bottom panel analysis for data with $\mathrm{RC}<0.8$ and year $<2011$. Left two columns estimates by surveys, central three columns pooled surveys estimates by RC indicators, and final three columns pooled surveys estimates for cases assuming $5 \%$ ageing errors. Values in red and italics with an asterisk are statistically not significant (with $\mathrm{p}>0.05$ ).

Table 5: Summary results of the integrated assessments for a) No ageing errors and b) $5 \%$ ageing errors. 


\section{List of Figures:}

Figure 1: Series of $\mathrm{Z}$ estimates by surveys for a) overall ages $\mathrm{Z1}+$ and $\mathrm{b}$ ) by age groups (Z1 and $\mathrm{Z2+}$ ).

Figure 2: Box-and-whisker plot for $Z$ by age (pooling survey estimates), for a) Overall $Z(Z 1+$ ), b) $Z$ at age $1(\mathrm{Z1})$; c) $\mathrm{Z}$ at age 2 and older (Z2+). Fishing legend: $\mathrm{N}=$ No Fishing (Closure period). $\mathrm{Y}=\mathrm{Fishing}$ period.

Figure 3: Fitted models (Model B1) of total Z estimates (Z1+) as a function of the relative catches between surveys, RCsurvey2 (two and single slope fitting - upper and medium panels) and RCJoint2 (bottom panels), for the complete set of data (left graphs) and for the subset of data (which removes Z values with $R C>0.8$ and Years $>2010$ ) (right graphs).

Figure 4: Fitted models for the $\mathrm{Z}$ by age $(\mathrm{Z1}$ and $\mathrm{Z2+})$ as a function of the relative catches between surveys, RCsurvey2 and RCJoint2 for the complete set of data (left graphs) and for the subset of data (which removes Z values with RC $>0.8$ and Years $>2010$ ) (right graphs). In all cases dashed lines correspond with age group $2+$ and continuous lines with age 1 . For the two slopes model the steeper lines correspond with the fitting of the $Z$ estimates from the DEPM series and the flatter lines refer to the fitting of $Z$ estimates from the acoustic series.

Figure 5: Response surfaces (total and partial contribution of the different auxiliary information) for the two objective functions, weighted sum of squares (WSSQ, left panels) and Log-Likelihood Ratios (LLHR, right panels) for a) a range of single natural mortality values (M1+), b), for a range of natural mortality at age 1 (M1), optimizing $\mathrm{M} 2+$, with a natural calendar year (January to December) and c) by age as before (case b) but with a calendar year from July to June.

Figure 6: Joint likelihood profile contour plots for natural mortality estimates by age (M1 and M2+), deduced from the two integrated assessments based either on weighted sum of squares (WSSQ, left graphs) or on log-likelihood ratios (LLHR right graphs), both based on a calendar year going from July 
to June, with information about the MLE estimates for $\mathrm{M} 1$ and $\mathrm{M} 2+$ (black dot) with their joint $95 \%$ confidence region (grey area) and MLE for a single natural mortality common to all ages (M1+) and its $95 \%$ confidence limits (black square point and lines along the 1:1 dotted line) for a) no ageing error default case (upper graphs) and b) for an assumption of $5 \%$ ageing errors (see text for details).

Figure 7: Comparison of natural mortality estimates by age ( 11 and $M 2+$ ) for the different estimation methods: a) for cases with no ageing errors b) for cases with $5 \%$ ageing errors. A 1:1 dotted line is included to check compatibility with the typical assumption of a single natural mortality.

There is one Appendix:

Appendix A: Integrated assessment of the Bay of Biscay 
1 Table 1: Matrix of age determination errors

2

3

\begin{tabular}{cllllr} 
& \multicolumn{6}{c}{ Assigned age } \\
\cline { 2 - 6 } True Age & $\mathbf{0}$ & $\mathbf{1}$ & $\mathbf{2}$ & $\mathbf{3 +}$ & Total \\
\hline $\mathbf{0}$ & 1.00 & 0.00 & 0.00 & 0.00 & 1.00 \\
$\mathbf{1}$ & 0.00 & 0.95 & 0.05 & 0.00 & 1.00 \\
$\mathbf{2}$ & 0.00 & 0.04 & 0.95 & 0.01 & 1.00 \\
$\mathbf{3 +}$ & 0.00 & 0.00 & 0.05 & 0.95 & 1.00
\end{tabular}

4

5

6

7 
8 Table 2: Mean $\mathrm{Z}$ estimates for $\mathrm{Z1}+, \mathrm{Z1}$ and $\mathrm{Z} 2+$ by fishing periods and surveys or jointly for the two surveys (pooled surveys), for the raw data (a-

9 upper tables) and assuming a 5\% ageing error (b- bottom tables). The fishery was closed between July 2005 (with only very small catches in 2006 ) and

10 December 2009

a) No Ageing Errors

Data Sources

$\mathrm{Z}$ Means by periods

$\mathrm{N}$ (complete data)

Complete Series

(1987-2012)

Fishing Period

\begin{tabular}{ccc}
\multicolumn{3}{c}{ DEPM Surveys } \\
\hline $\mathbf{Z 1 +}$ & $\mathbf{Z 1}$ & $\mathbf{Z 2 +}$ \\
\hline 19 & 19 & 19
\end{tabular}

\begin{tabular}{ccc}
\multicolumn{3}{c}{ ACOUSTIC Surveys } \\
\hline $\mathbf{Z 1 +}$ & $\mathbf{Z 1}$ & $\mathbf{Z 2 +}$ \\
\hline 14 & 13 & 13
\end{tabular}

\begin{tabular}{ccc}
\multicolumn{3}{c}{ Pooled Surveys } \\
\hline $\mathbf{Z 1 +}$ & $\mathbf{Z 1}$ & $\mathbf{Z 2 +}$ \\
\hline 33 & 32 & 32 \\
$\mathbf{1 . 4 0}$ & $\mathbf{1 . 1 3}$ & $\mathbf{2 . 0 5}$ \\
$9 \%$ & $14 \%$ & $7 \%$ \\
$\mathbf{1 . 6 6}$ & $\mathbf{1 . 4 4}$ & $\mathbf{2 . 2 6}$ \\
$9 \%$ & $11 \%$ & $7 \%$ \\
$\mathbf{0 . 8 1}$ & $\mathbf{0 . 4 5}$ & $\mathbf{1 . 5 9}$ \\
$13 \%$ & $50 \%$ & $12 \%$ \\
$\mathbf{0 . 8 8}$ & $\mathbf{0 . 6 6}$ & $\mathbf{1 . 6 3}$ \\
$\mathbf{6 \%}$ & $11 \%$ & $19 \%$
\end{tabular}

b) $5 \%$ Ageing Errors

Data Sources

$Z$ Means by periods

$\mathrm{N}$ (complete data)

$\begin{array}{lll}1.48 & 1.22 & 2.32\end{array}$

$\begin{array}{lll}1.30 & 0.99 & 1.65\end{array}$

$14 \% \quad 22 \% \quad 11 \%$

$1.61 \quad 1.38 \quad 1.78$

$13 \% \quad 11 \% \quad 15 \%$

$\begin{array}{lll}0.76 & 0.35 & 1.44\end{array}$

$17 \% \quad 106 \% \quad 14 \%$

$0.86 \quad 0.70 \quad 1.35$

Complete Series

Fishing Period

CV $12 \% \quad 15 \% \quad 8 \%$

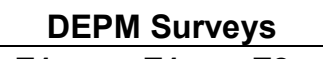

ACOUSTIC Surveys

\begin{tabular}{ccc}
\hline $\mathbf{Z 1 +}$ & $\mathbf{Z 1}$ & $\mathbf{Z 2 +}$ \\
\hline 14 & 13 & 13 \\
$\mathbf{1 . 5 6}$ & $\mathbf{1 . 2 4}$ & $\mathbf{1 . 4 7}$ \\
$\mathbf{1 7 \%}$ & $21 \%$ & $14 \%$ \\
$\mathbf{1 . 9 5}$ & $\mathbf{1 . 6 8}$ & $\mathbf{1 . 5 3}$ \\
$\mathbf{1 7 \%}$ & $14 \%$ & $20 \%$ \\
$\mathbf{0 . 8 7}$ & $\mathbf{0 . 5 3}$ & $\mathbf{1 . 3 8}$ \\
$\mathbf{1 6 \%}$ & $\mathbf{7 6 \%}$ & $15 \%$ \\
$\mathbf{0 . 9 8}$ & $\mathbf{0 . 9 2}$ & $\mathbf{1 . 2 7}$ \\
$\mathbf{1 4 \%}$ & $\mathbf{2 0 \%}$ & $\mathbf{2 8 \%}$
\end{tabular}

\begin{tabular}{ccc}
\multicolumn{3}{c}{ Pooled Surveys } \\
\hline Z1+ & $\mathbf{Z 1}$ & $\mathbf{Z 2 +}$ \\
\hline 33 & 32 & 32 \\
$\mathbf{1 . 6 9}$ & $\mathbf{1 . 4 8}$ & $\mathbf{1 . 8 9}$ \\
$9 \%$ & $12 \%$ & $7 \%$ \\
$\mathbf{2 . 0 2}$ & $\mathbf{1 . 8 5}$ & $\mathbf{2 . 0 5}$ \\
$\mathbf{9} \%$ & $10 \%$ & $8 \%$ \\
$\mathbf{0 . 9 5}$ & $\mathbf{0 . 6 5}$ & $\mathbf{1 . 5 2}$ \\
$12 \%$ & $35 \%$ & $13 \%$ \\
$\mathbf{1 . 0 1}$ & $\mathbf{0 . 8 8}$ & $\mathbf{1 . 5 8}$ \\
$10 \%$ & $12 \%$ & $21 \%$
\end{tabular}

CV $\quad 10 \% \quad 1.95 \quad 2.36$

$\begin{array}{llll} & 1.03 & 0.78 & 1.66\end{array}$

(2005-2009) CV 18\% 35\% 20\%

(2007-2009) CV 18\% $18 \% \quad 30 \%$

$14 \% \quad 20 \% \quad 28 \%$ 
13 Table 3: Summary results from linear models on overall mortality $(\mathrm{Z} 1+)$ and estimates of overall natural mortality $(\mathrm{M} 1+)$ from the intercept of the

14 linear models. a) Upper panel analysis for all data, b) bottom panel analysis for data with $\mathrm{RC}<0.8$ and year $<2011$. Left two columns estimates by

15 surveys, central three columns pooled surveys estimates by RC indicators, and final three columns pooled surveys estimates for cases assuming $5 \%$

16 ageing errors. Values in red and italics with an asterisk are statistically not significant (with $\mathrm{p}>0.05$ ).

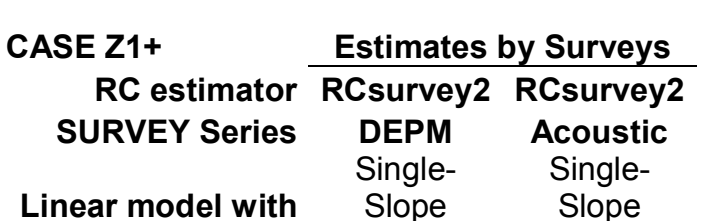

a) Complete set of Data $\backslash \mathrm{N}$ :

$\begin{array}{cccc}\text { Intercept (= M1+) } & & \mathbf{1 . 1 3 6} & \mathbf{0 . 9 5 4} \\ & \text { CV } & 26 \% & 26 \% \\ \text { RC slope coefficient } & & 0.656^{*} & 2.380^{*} \\ & \text { CV } & 69 \% & 55 \%\end{array}$

Additive Slope component

Model P-Value

$$
\text { R-Squared }
$$

CV

b) Subset of Data I

Intercept (= M1+)

$\mathrm{RC}$ slope coefficient

$\begin{array}{ccc} & \mathbf{0 . 7 6 2} & \mathbf{0 . 8 8 4} \\ \text { CV } & 45 \% & 32 \% \\ & 1.787 & 2.583^{*} \\ \text { CV } & 41 \% & 54 \%\end{array}$

Additive Slope component

$$
\text { Model P-Value }
$$

CV

$$
\text { R-Squared }
$$

Pooled Estimates

\begin{tabular}{ccc}
\multicolumn{3}{c}{ Pooled Estimates } \\
\hline RCsurvey2 & RCsurvey2 & RCJoint2 \\
Pooled & Pooled & Pooled \\
Two- & Single- & Single- \\
Slopes & Slope & Slope
\end{tabular}

\begin{tabular}{|c|c|c|}
\hline \multicolumn{3}{|c|}{$\begin{array}{l}\text { Pooled Estimates \& } \\
5 \% \text { Ageing Errors }\end{array}$} \\
\hline RCsurvey2 & RCsurvey2 & RCJoint2 \\
\hline $\begin{array}{l}\text { Pooled } \\
\text { Two- } \\
\text { Slopes }\end{array}$ & $\begin{array}{l}\text { Pooled } \\
\text { Single- } \\
\text { Slope }\end{array}$ & $\begin{array}{l}\text { Pooled } \\
\text { Single- } \\
\text { Slope }\end{array}$ \\
\hline
\end{tabular}

$\begin{array}{ccc}33 & 33 & 26 \\ \mathbf{1 . 0 5 2} & \mathbf{1 . 1 5 2} & \mathbf{0 . 8 8 5} \\ 19 \% & 15 \% & 20 \% \\ 1.991^{*} & 0.694 & 1.633 \\ 62 \% & 49 \% & 33 \% \\ -0.915^{*} & & \\ 81 \% & & \\ 0.0837 & 0.0496 & 0.0064 \\ 15 \% & 12 \% & 27 \%\end{array}$

$\begin{array}{ccc}25 & 25 & 22 \\ \mathbf{0 . 8 2 6} & \mathbf{0 . 9 2 0} & \mathbf{0 . 7 8 1} \\ 26 \% & 22 \% & 22 \% \\ 2.804 & 1.651 & 1.831 \\ 44 \% & 33 \% & 27 \% \\ -1.130^{*} & & \\ 96 \% & & \\ 0.015 & 0.006 & 0.0013 \\ 32 \% & 25 \% & 41 \%\end{array}$

$\begin{array}{ccc}33 & 33 & 26 \\ 1.137 & 1.301 & 1.001 \\ 20 \% & 15 \% & 23 \% \\ 3.107 & 1.048 & 2.188 \\ 44 \% & 36 \% & 32 \% \\ -1.951^{*} & & \\ 65 \% & & \\ 0.0119 & 0.0099 & 0.0043 \\ 26 \% & 20 \% & 29 \%\end{array}$

$\begin{array}{ccc}24 & 24 & 22 \\ \mathbf{0 . 9 3 6} & \mathbf{1 . 0 7 8} & \mathbf{0 . 9 4 1} \\ 29 \% & 23 \% & 27 \% \\ 3.829 & 2.103 & 2.309 \\ 38 \% & 34 \% & 31 \% \\ -1.731^{*} & & \\ 75 \% & & \\ 0.014 & 0.0079 & 0.0039 \\ 34 \% & 28 \% & 35 \%\end{array}$


18 Table 4: Summary results from linear models on estimates of $Z$ by age (from Age 1 to 2 and from Age 2+ to 3+), with estimates of M1 and M2+ from

19 the intercepts of the fitted models. a) Upper panel analysis for all data, b) bottom panel analysis for data with RC $<0.8$ and year $<2011$. Left two

20 columns estimates by surveys, central three columns pooled surveys estimates by RC indicators, and final three columns pooled surveys estimates for

21 cases assuming 5\% ageing errors. Values in red and italics with an asterisk are statistically not significant (with $\mathrm{p}>0.05$ ).

\section{CASE $Z$ by ages Estimates by Surveys RC estimator RCsurvey2 RCsurvey2 SURVEY Series \\ Linear model with

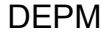 \\ Single- \\ Slope}

a) Complete set of Data $\backslash \mathrm{N}$ : Intercept1 (= M1)

OLD (addition for $\mathrm{M} 2+$ )

Intercept2 (= M2+)

$\mathrm{RC}$ slope coefficient

Additive Slope component

Model P-Value

$$
\text { R-Squared }
$$

$\begin{array}{cc}38 & 26 \\ \mathbf{0 . 9 5 1} & \mathbf{0 . 9 3 3} \\ 23 \% & 26 \% \\ 0.999 & 0.644 \\ 26 \% & 46 \% \\ \mathbf{1 . 9 5 1} & \mathbf{1 . 5 7 7} \\ 18 \% & 24 \% \\ 0.527 & 0.412^{*} \\ 45 \% & 234 \%\end{array}$

b) Subset of Data

Intercept1 (= M1)

OLD (addition for M2+)

ntercept2 (= M2+)

$\begin{array}{ccc}\text { I N: } & 23 & 22 \\ & \mathbf{0 . 6 8 2} & \mathbf{0 . 8 6 1} \\ \text { CV } & 44 \% & 32 \% \\ \text { C) } & 0.754 & 0.610^{*} \\ \text { CV } & 41 \% & 54 \% \\ & 1.436 & 1.471\end{array}$

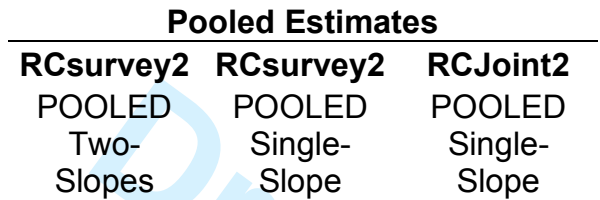

$\begin{array}{ccc}64 & 64 & 50 \\ \mathbf{0 . 9 4 0} & \mathbf{0 . 9 0 0} & \mathbf{0 . 8 2 2} \\ 17 \% & 17 \% & 23 \% \\ 0.854 & 0.839 & 0.908 \\ 23 \% & 23 \% & 25 \% \\ \mathbf{1 . 7 9 4} & \mathbf{1 . 7 3 8} & \mathbf{1 . 7 3 0} \\ 14 \% & 14 \% & 17 \% \\ -0.009^{*} & 0.634 & 0.818^{*} \\ 9593 \% & 31 \% & 64 \% \\ 0.621^{*} & & \\ 128 \% & & \\ 0.1942 & 0.0000 & 0.0002 \\ 15 \% & 35 \% & 30 \%\end{array}$

45
0.780
$25 \%$
0.684
$32 \%$
1.464

$\begin{array}{cc}45 & 40 \\ \mathbf{0 . 7 4 2} & \mathbf{0 . 5 8 2} \\ 26 \% & 35 \% \\ 0.662 & 0.997 \\ 33 \% & 23 \% \\ \mathbf{1 . 4 0 3} & \mathbf{1 . 5 8 0}\end{array}$

Pooled Estimates \& 5\% Ageing

\begin{tabular}{ccc}
\multicolumn{3}{c}{ Errors } \\
\hline RCsurvey2 & RCsurvey2 & RCJoint2 \\
POOLED & POOLED & POOLED \\
Two- & Single- & Single- \\
Slopes & Slope & Slope
\end{tabular}

$\begin{array}{ccc}64 & 64 & 50 \\ 1.373 & 1.319 & 1.113 \\ 12 \% & 12 \% & 19 \% \\ 0.339^{*} & 0.313^{*} & 0.448^{*} \\ 62 \% & 67 \% & 56 \% \\ 1.713 & 1.631 & 1.561 \\ 16 \% & 16 \% & 21 \% \\ -0.474^{*} & 0.418 & 0.878^{*} \\ 172 \% & 33 \% & 62 \% \\ 0.873^{*} & & \\ 90 \% & & \\ 0.0045 & 0.0026 & 0.048 \\ 15 \% & 18 \% & 12 \%\end{array}$

$\begin{array}{ccc}45 & 45 & 40 \\ 1.091 & 1.058 & \mathbf{0 . 8 8 3} \\ 20 \% & 20 \% & 26 \% \\ 0.261^{*} & 0.221^{*} & 0.546 \\ 93 \% & 110 \% & 48 \% \\ 1.352 & 1.279 & 1.429\end{array}$




\begin{tabular}{|c|c|c|c|c|c|c|c|c|}
\hline $\mathrm{CV}$ & $30 \%$ & $29 \%$ & $20 \%$ & $21 \%$ & $19 \%$ & $24 \%$ & $25 \%$ & $24 \%$ \\
\hline RC slope coefficient & 1.748 & $0.629^{*}$ & $0.748^{*}$ & 1.535 & 1.710 & $0.507^{*}$ & 1.413 & 1.871 \\
\hline $\mathrm{CV}$ & $36 \%$ & $163 \%$ & $116 \%$ & $32 \%$ & $35 \%$ & $171 \%$ & $38 \%$ & $36 \%$ \\
\hline Additive Slope component & & & $0.878^{*}$ & & & $1.079^{*}$ & & \\
\hline $\mathrm{CV}$ & & & $91 \%$ & & & $76 \%$ & & \\
\hline Model P-Value & 0.0044 & 0.1474 & 0.1474 & 0.0002 & 0.0001 & 0.0306 & 0.0115 & 0.0069 \\
\hline R-Squared & $42 \%$ & $18 \%$ & $18 \%$ & $33 \%$ & $41 \%$ & $14 \%$ & $16 \%$ & $24 \%$ \\
\hline
\end{tabular}


24 Table 5: Summary results of the integrated assessments for a) No ageing errors and b) 5\%

25 ageing errors.

\begin{tabular}{|c|c|c|c|c|}
\hline & \multicolumn{2}{|c|}{ a) No ageing errors } & \multicolumn{2}{|c|}{ b) $5 \%$ ageing errors } \\
\hline \multicolumn{5}{|l|}{ Single $M$} \\
\hline & WSSQ & LLHR & WSSQ & LLHR \\
\hline Mean M1+ & 1.148 & 1.000 & 1.188 & 1.044 \\
\hline CV (aprox) & $5.4 \%$ & $4.3 \%$ & $6 \%$ & $4 \%$ \\
\hline Objective Function & 42.3093 & 308.5502 & 50.1018 & 317.7327 \\
\hline Total LogLikelihood & -88.1095 & -490.0735 & -126.5522 & -491.5557 \\
\hline AIC & 362.2191 & 1166.1470 & 439.1043 & 1169.1115 \\
\hline $\mathrm{AlCc}$ & 419.3563 & 1223.2842 & 496.2416 & 1226.2487 \\
\hline \multirow[t]{2}{*}{ M. by ages } & \multicolumn{2}{|c|}{ M. (January to December) } & \multicolumn{2}{|c|}{ M. (January to December) } \\
\hline & WSSQ & LLHR & WSSQ & LLHR \\
\hline Mean M1 & 0.172 & 0.262 & 0.733 & 0.582 \\
\hline CV (aprox) & $88 \%$ & $44 \%$ & $36 \%$ & $21 \%$ \\
\hline Mean M2+ & 1.467 & 1.376 & 1.326 & 1.263 \\
\hline CV (aprox) & $7.5 \%$ & $6.1 \%$ & $9 \%$ & $6 \%$ \\
\hline Objective Function & 38.1907 & 270.0725 & 49.1966 & 64.0470 \\
\hline Total LogLikelihood & -73.1320 & -451.5218 & -123.5479 & -478.6685 \\
\hline AIC & 334.2641 & 1091.0436 & 435.0958 & 1145.3369 \\
\hline $\mathrm{AICc}$ & 392.8215 & 1149.6009 & 493.6532 & 1203.8943 \\
\hline LogLikelihood ratio vs single $\mathrm{M}$ & 14.9775 & 38.5517 & 3.0043 & 12.8873 \\
\hline Probability of the Ratio & 0.0000 & 0.0000 & 0.0496 & 0.0000 \\
\hline \multirow[t]{2}{*}{ M. by ages } & \multicolumn{2}{|c|}{ M. (July to June) } & \multicolumn{2}{|c|}{ M. (July to June) } \\
\hline & WSSQ & LLHR & WSSQ & LLHR \\
\hline Mean M1 & 0.700 & 0.712 & 0.979 & 0.853 \\
\hline CV (aprox) & $19 \%$ & $9 \%$ & $15 \%$ & $8 \%$ \\
\hline Mean M2+ & 1.518 & 1.429 & 1.351 & 1.299 \\
\hline CV (aprox) & $8.0 \%$ & $6.4 \%$ & $9 \%$ & $7 \%$ \\
\hline Objective Function & 38.5194 & 271.5586 & 49.2783 & 305.014 \\
\hline Total LogLikelihood & -74.6555 & -452.8735 & -123.7316 & -478.888 \\
\hline $\mathrm{AIC}$ & 337.3109 & 1093.7471 & 435.4632 & 1145.7757 \\
\hline $\mathrm{AlCc}$ & 395.8683 & 1152.3045 & 494.0206 & 1204.3331 \\
\hline LogLikelihood ratio vs single M & 13.4541 & 37.1999 & 2.8205 & 12.6679 \\
\hline Probability of the Ratio & 0.0000 & 0.0000 & 0.0596 & 0.0000 \\
\hline
\end{tabular}


a) $\mathrm{Z} 1+$

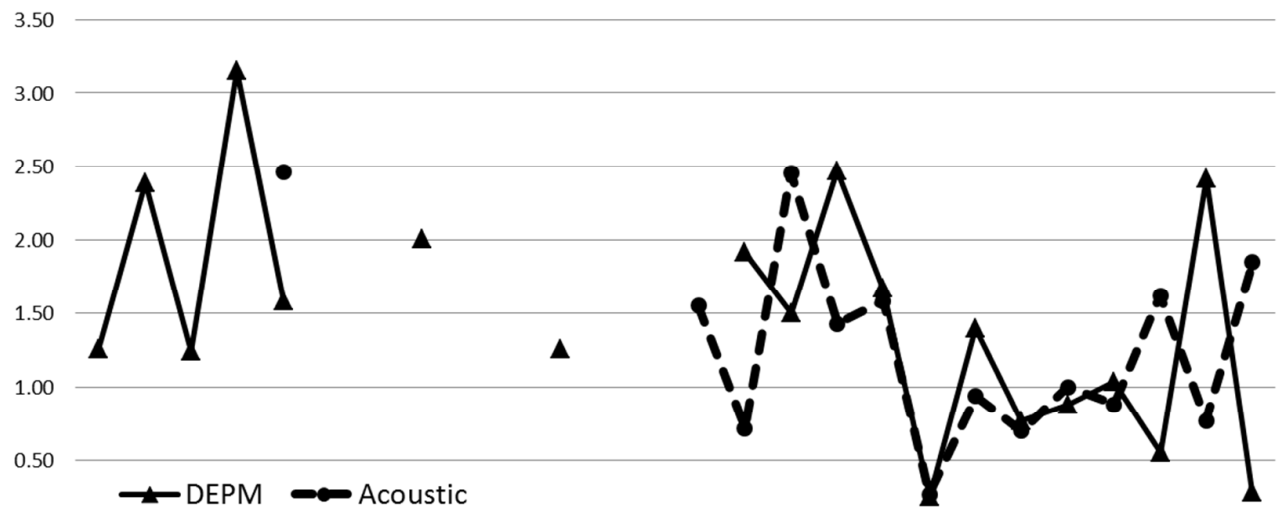

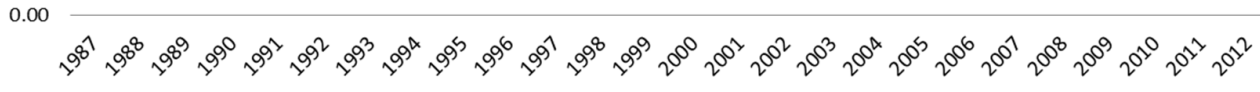

b) $\mathrm{Z}$ by age groups

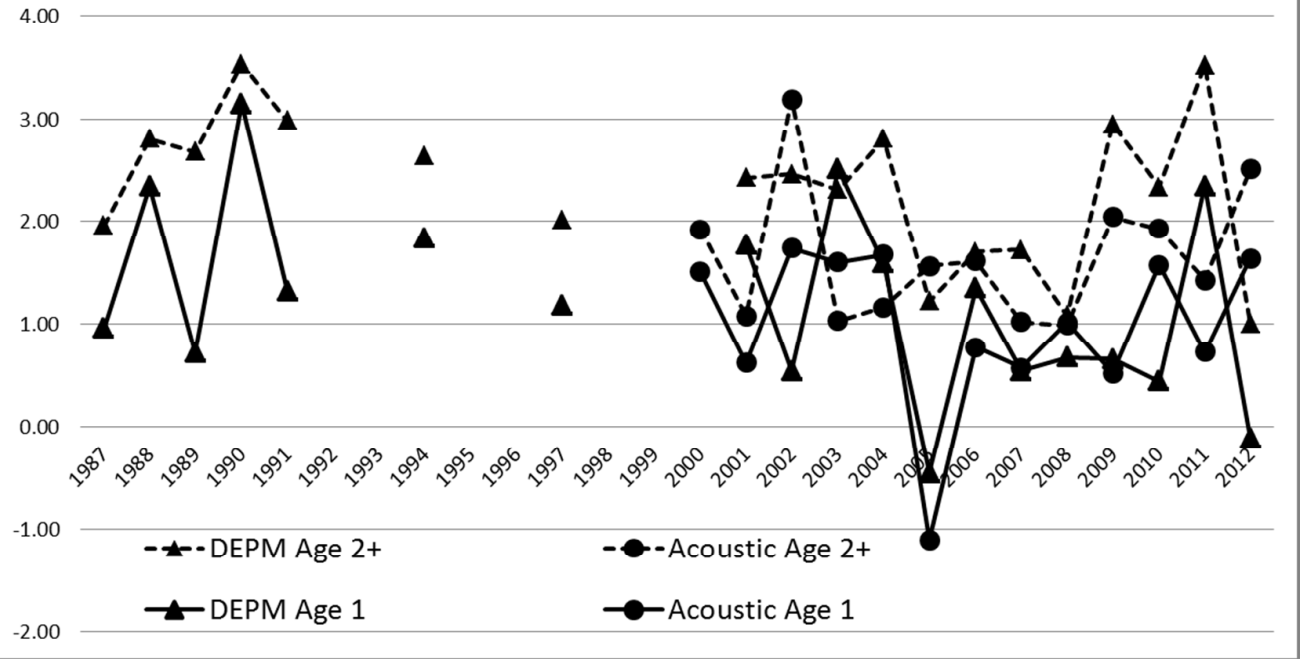

31 Figure 1: Series of $Z$ estimates by surveys for a) overall ages $Z 1+$ and b) by age groups ( $Z 1$ and $\mathrm{Z} 2+)$. 
a) Overall $\mathrm{Z}(\mathrm{Z} 1+)$ :

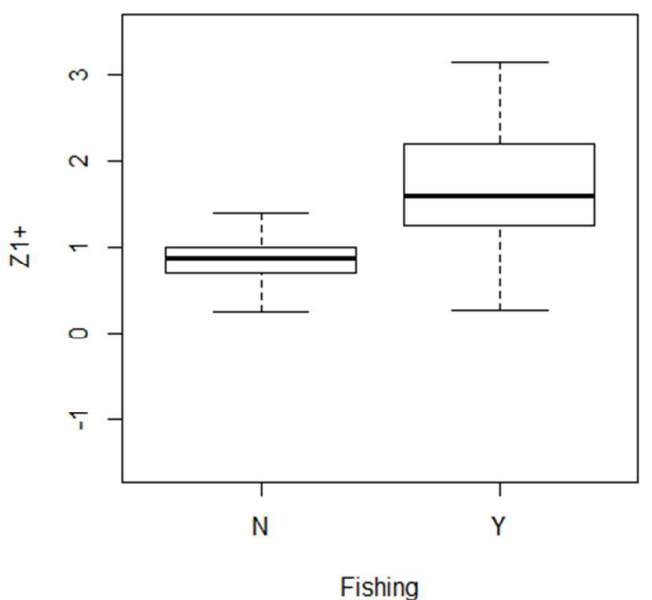

b) $\mathrm{Z}$ at age $1(\mathrm{Z1})$ :

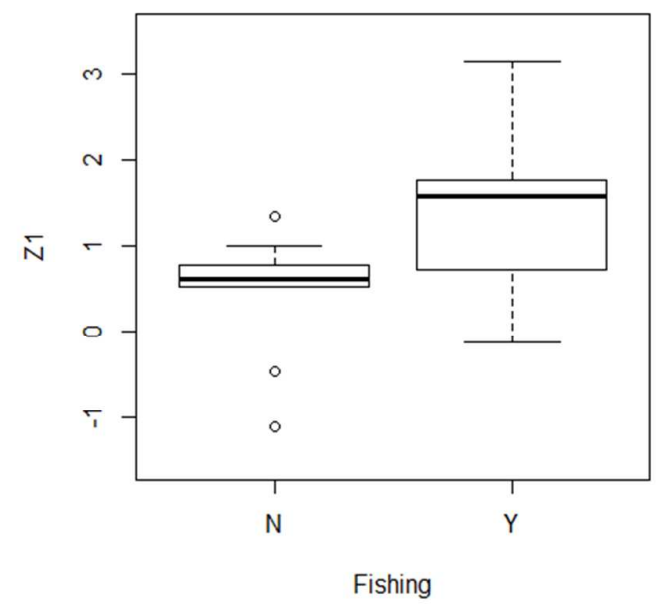

c) $\mathrm{Z}$ at age 2 and older $(\mathrm{Z} 2+)$ :

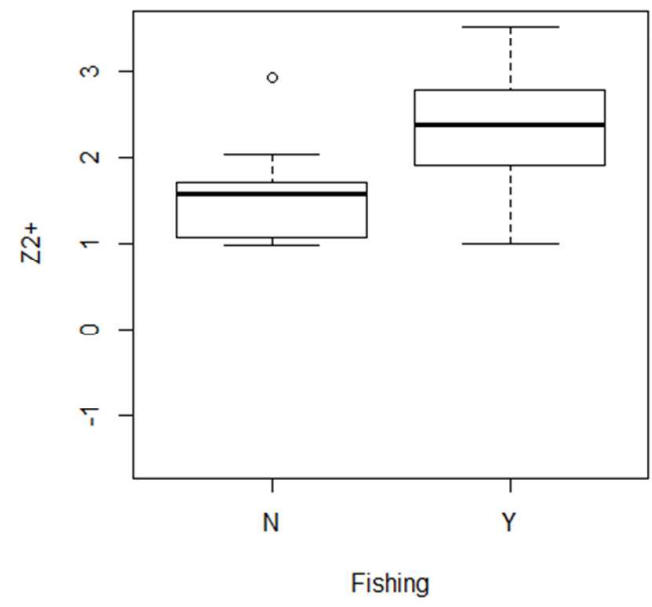

37 Figure 2: Box-and-whisker plot for $Z$ by age (pooling survey estimates), for a) Overall $Z(Z 1+), b) Z$ at age $1(Z 1)$; c) $Z$ at age 2 and older ( $Z 2+)$.

38 Fishing legend: $\mathrm{N}=$ No Fishing (Closure period). $\mathrm{Y}=$ Fishing period. 

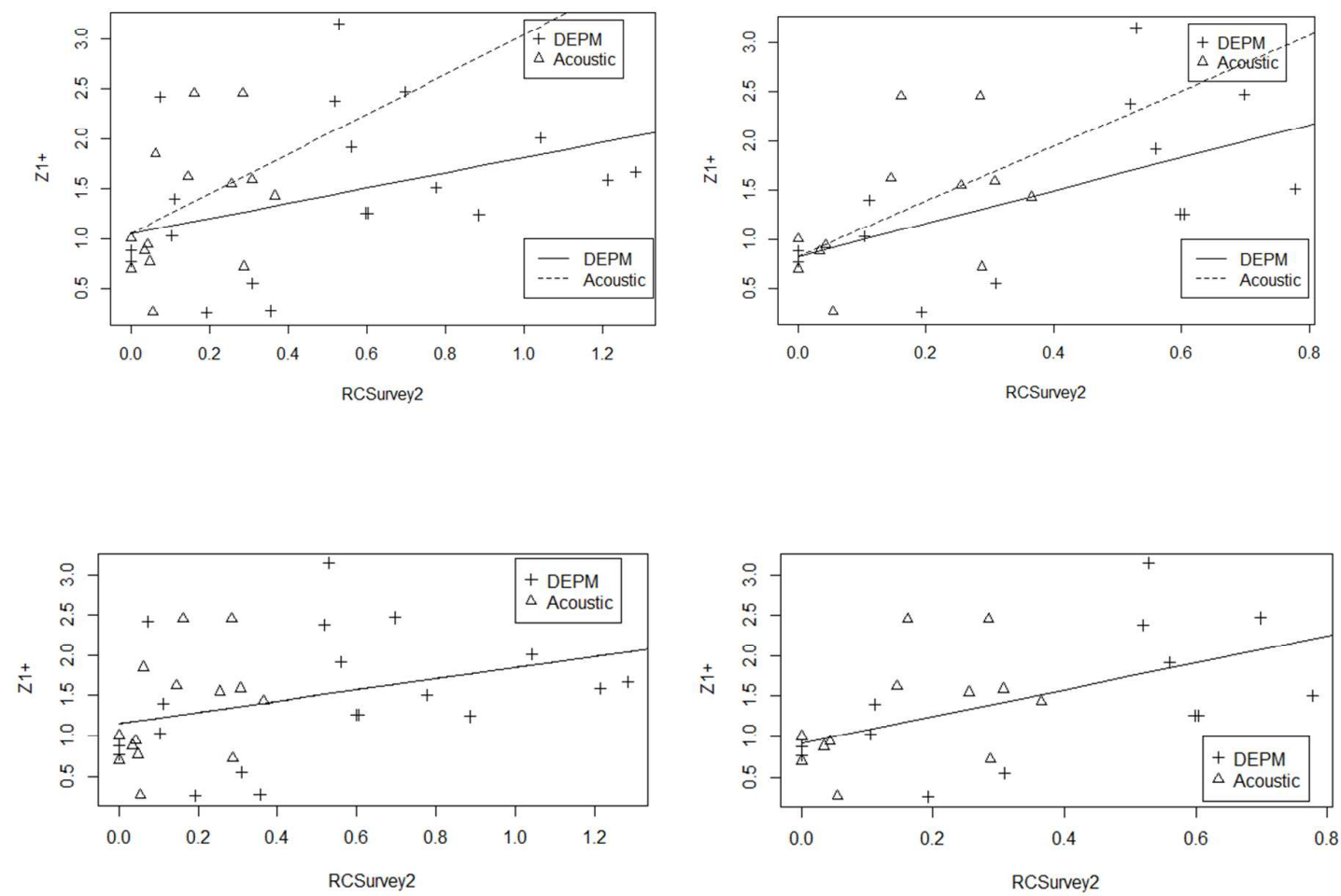

42
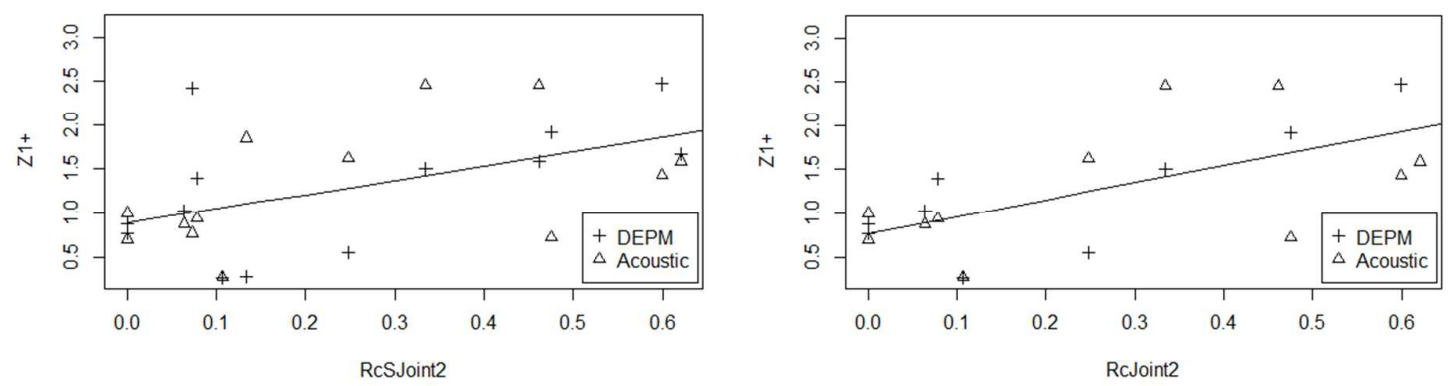

Figure 3: Fitted models (Model B1) of total Z estimates $(\mathrm{Z} 1+)$ as a function of the relative catches between surveys, RCsurvey2 (two and single slope fitting - upper and medium panels) and RCJoint2 (bottom panels), for the complete set of data (left graphs) and for the subset of 47 data (which removes $Z$ values with $\mathrm{RC}>0.8$ and Years $>2010$ ) (right graphs). 

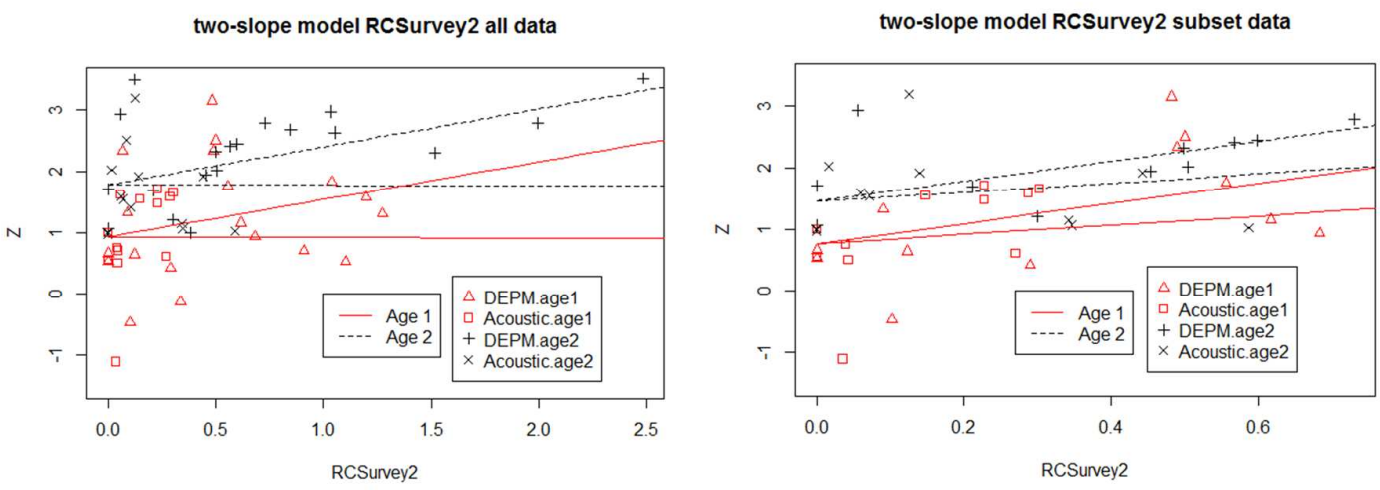

49
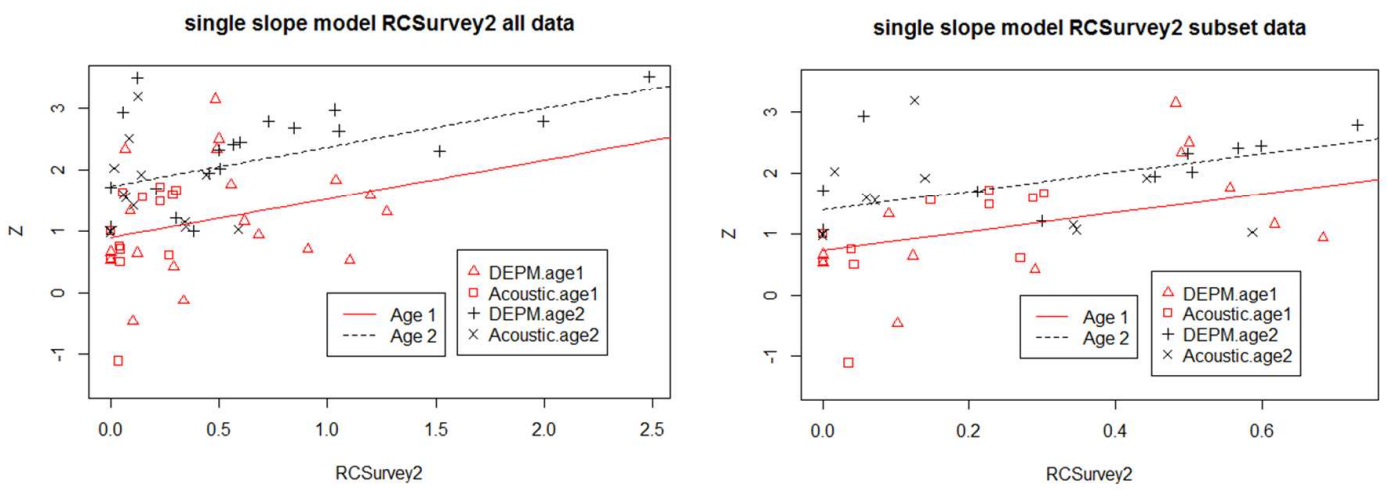

50
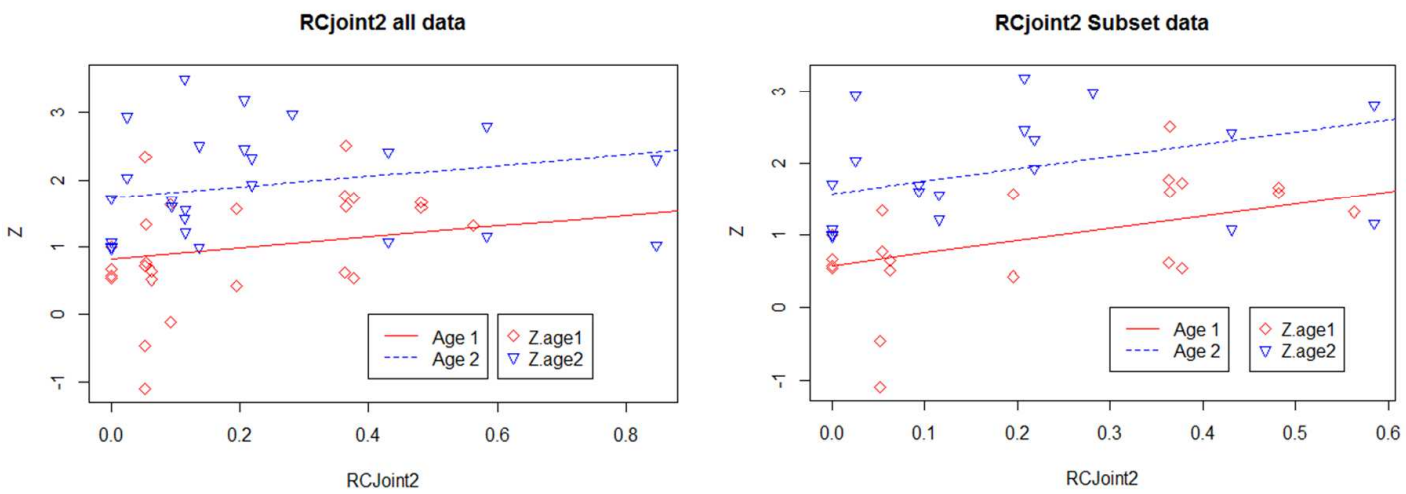

Figure 4: Fitted models for the $\mathrm{Z}$ by age $(\mathrm{Z1}$ and $\mathrm{Z2}+$ ) as a function of the relative catches between surveys, RCsurvey2 and RCJoint2 for the complete set of data (left graphs) and for the subset of data (which removes $Z$ values with $\mathrm{RC}>0.8$ and Years $>2010$ ) (right graphs). In all cases dashed lines correspond with age group $2+$ and continuous lines with age 1. For the two slopes model the steeper lines correspond with the fitting of the $Z$ estimates from the DEPM series and the flatter lines refer to the fitting of $\mathrm{Z}$ estimates from the acoustic series. 
60

61

62

63

64

65

66

67

68

69

70

WSSQ minimization

LLHR minimization

a) $\mathrm{M} 1+$

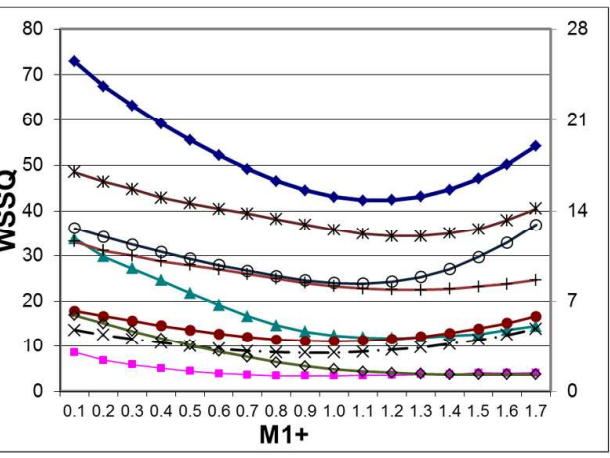

b) $\mathrm{M} 1 \& \mathrm{M} 2+(\mathrm{Jan}-\mathrm{Dec})$

M1
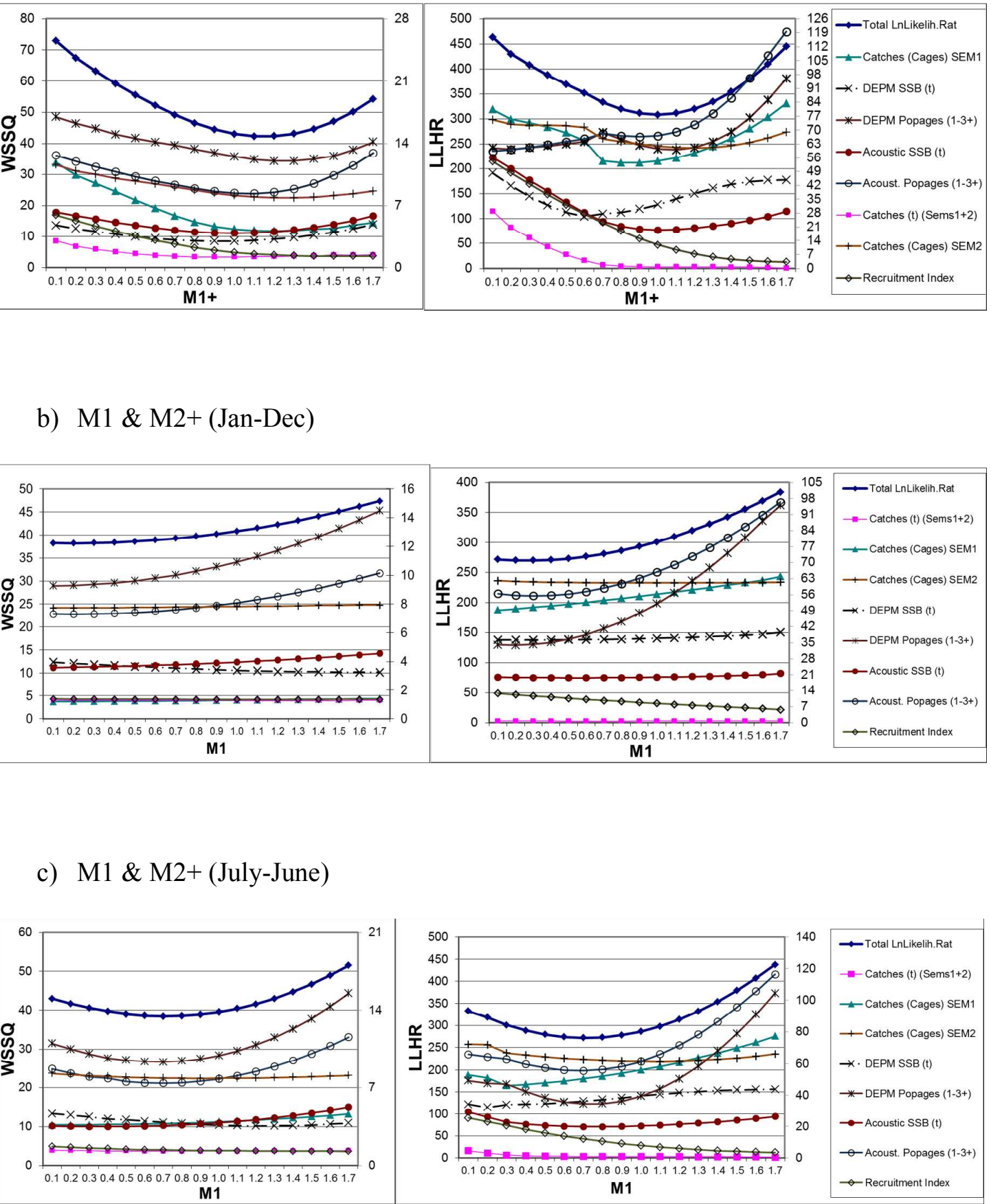

71 information) for the two objective functions, weighted sum of squares (WSSQ, left panels)

72 and Log-Likelihood Ratios (LLHR, right panels) for a) a range of single natural mortality 
73 values $(\mathrm{M} 1+), \mathrm{b})$, for a range of natural mortality at age 1 (M1), optimizing $\mathrm{M} 2+$, with a

74 natural calendar year (January to December) and c) by age as before (case b) but with a 75 calendar year from July to June.

76

77 
78

79

80

WSSQ minimization

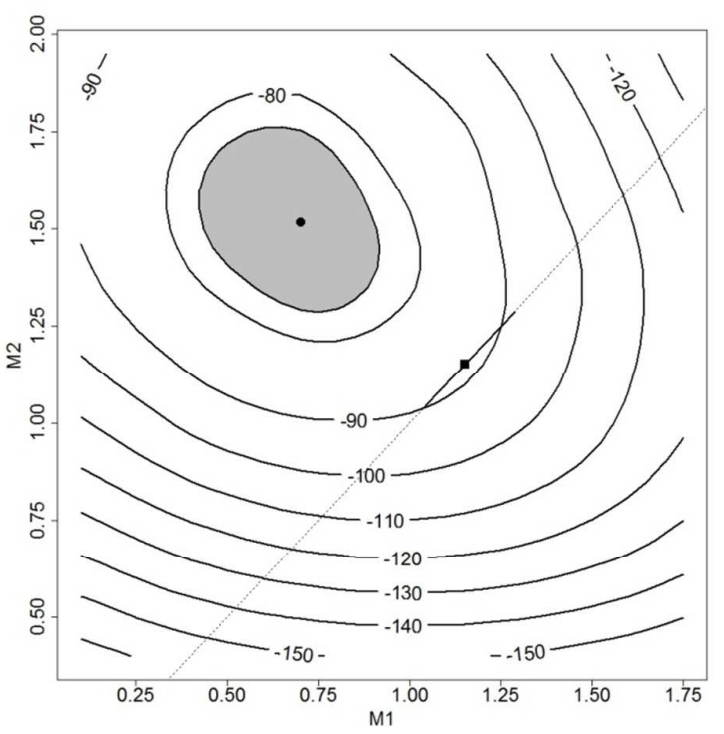

81

82

83

84

85

86

87

88

Figure 6

a) No Errors

\section{(12}

b) $5 \%$ Ageing Errors

WSSQ minimization

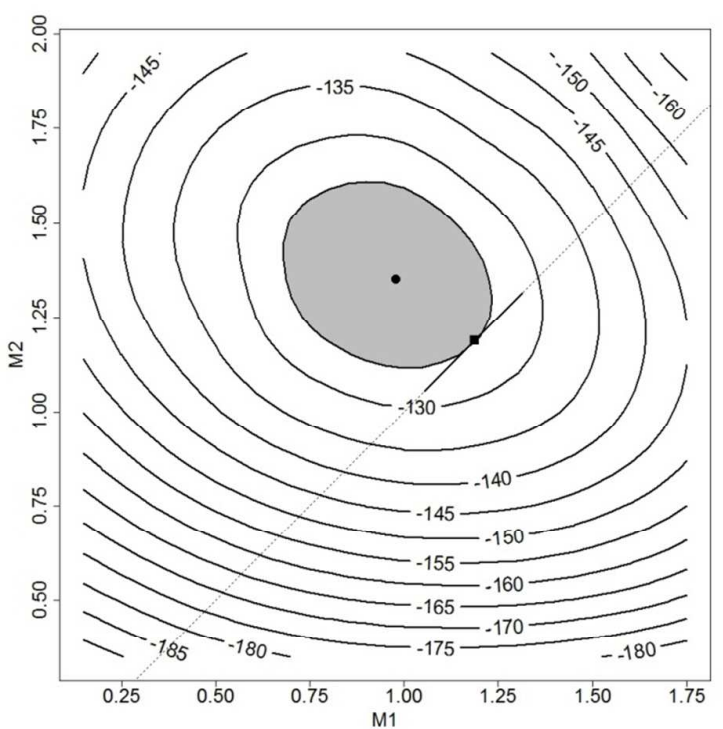

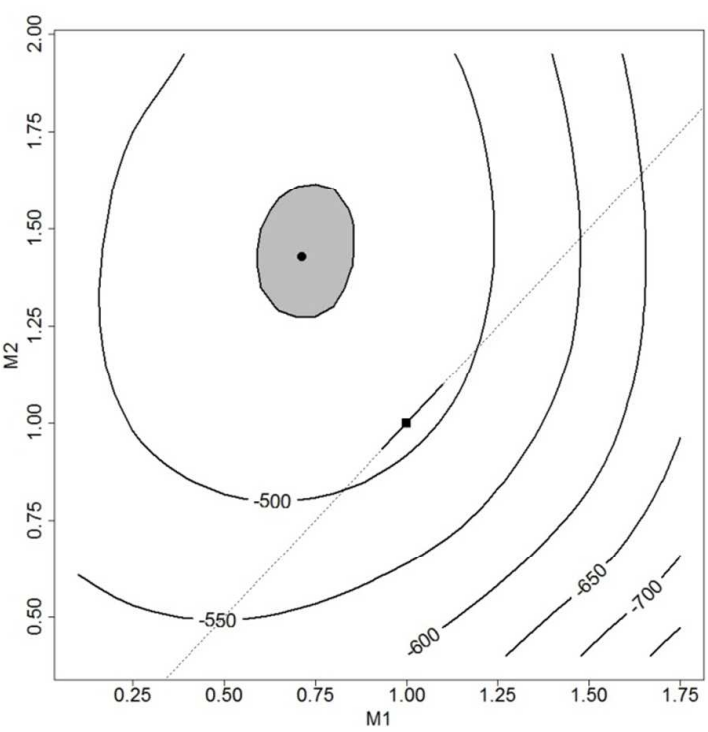

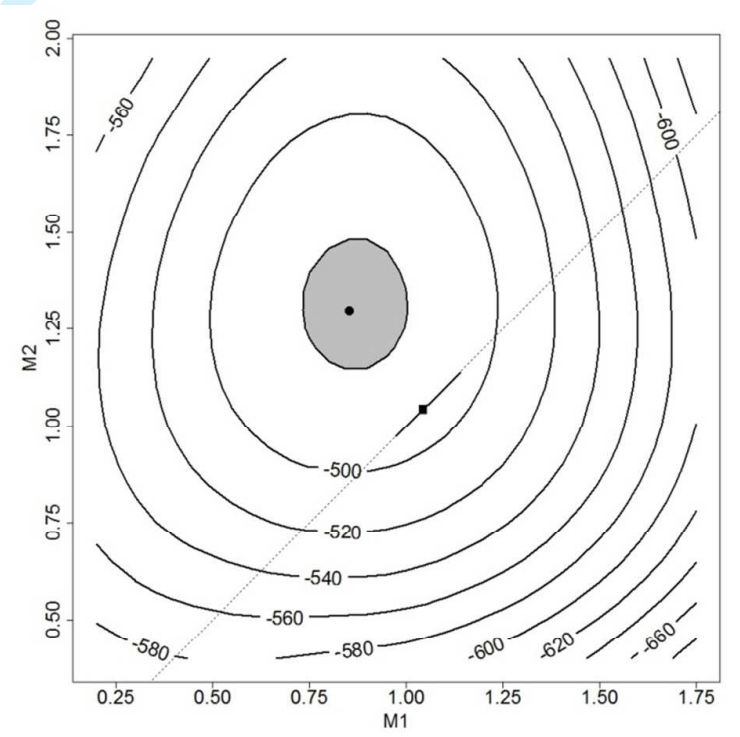

Figure 6: Joint likelihood profile contour plots for natural mortality estimates by age (M1 and $\mathrm{M} 2+$ ), deduced from the two integrated assessments based either on weighted sum of squares (WSSQ, left graphs) or on log-likelihood ratios (LLHR right graphs), both based on a calendar 
89 year going from July to June, with information about the MLE estimates for M1 and M2+

90 (black dot) with their joint 95\% confidence region (grey area) and MLE for a single natural

91 mortality common to all ages (M1+) and its 95\% confidence limits (black square point and

92 lines along the 1:1 dotted line) for a) no ageing error default case (upper graphs) and b) for an

93 assumption of 5\% ageing errors (see text for details).

94

95 
Figure 7:

98

99

a) No ageing errors

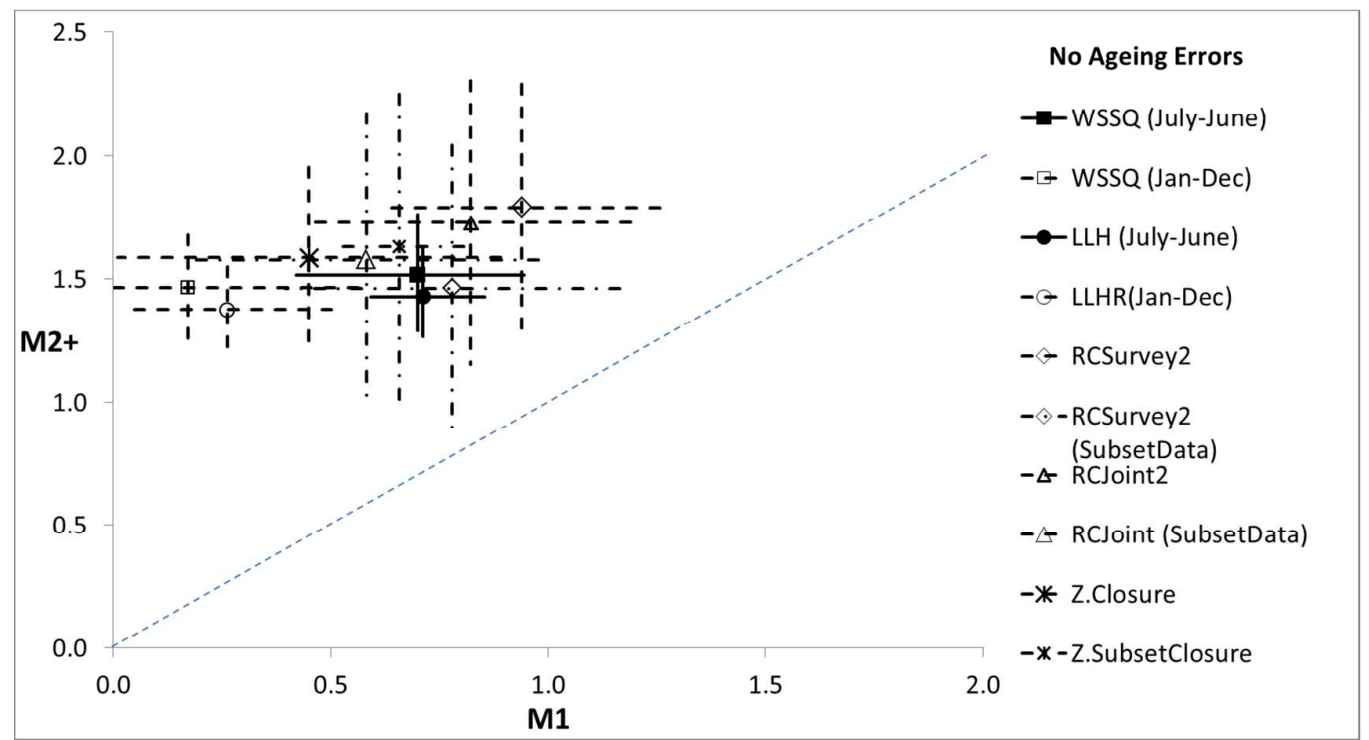

101

b) $5 \%$ Ageing Errors

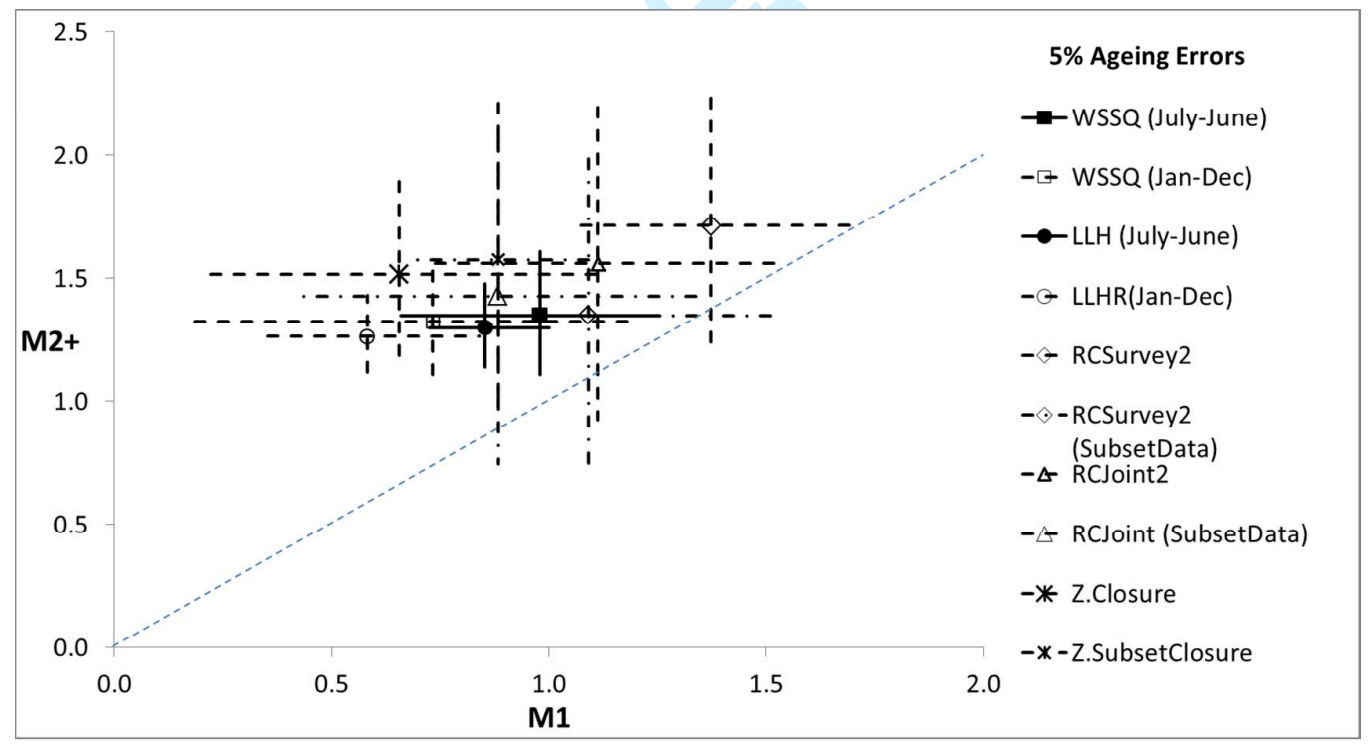

102

Figure 7: Comparison of natural mortality estimates by age (M1 and M2+) for the different

104 estimation methods: a) for cases with no ageing errors b) for cases with $5 \%$ ageing errors. A

$105 \quad 1: 1$ dotted line is included to check compatibility with the typical assumption of a single

106 natural mortality 
1 Appendix A to Uriarte et al. submission 16/02/2015 to CJFAS (29/09/2015)

3 Integrated assessment of the Bay of Biscay:

4 We applied a Seasonal Integrated Catch at Age analysis (SICA) on a six-monthly

5 basis, fitting different selectivity patterns to the international fleet operating during

6 each half of the year and tuning the population to the abundance indexes available

7 (as used by ICES 2013): the two spring surveys (Acoustic and DEPM index) and a

8 recruitment acoustic survey on juveniles in autumn. Age structure of both catches

9 and spring surveys go up to age group 3+ (grouping ages 3 and older). The survey

10 on juveniles produces a single index at age 0 in the autumn of any year $\mathrm{Y}$ which is

11 entered as an indicator of the strength of the recruits at age 1 in January of year

$12 \mathrm{Y}+1$.

14 Biomass indexes are dealt with as relative indexes proportional to abundance for

15 which no additional catchability is estimated. In addition, in SICA, a Qflat

16 catchability model is implemented for the purposes of this analysis (i.e. forcing

17 catchability at age of the surveys to be equal for all ages).

19 We have fitted SICA with the Qflat catchability model for the two surveys allowing

20 to optimize for $\mathrm{M} 1+$ (a single natural mortality for all ages) or for M1 and M2+ (i.e.

21 one $\mathrm{M}$ for age 1 and another for the plus group of ages 2 and older); the latter is

22 essayed in order to find out what natural mortality pattern optimizes the fitting. In

23 practice, as the model is implemented in Excel, a systematic optimization procedure

24 across a range of M1+ or M1 (including the optimization of M2+) was made.

25 Initially a range of $\mathrm{M}$ between 0.1 and 1.7 , in steps of 0.1 , was covered. Later, a 
systematic 2D mapping around the optimum was carried out in stopes of 0.05 . The

results show the values of the objective function optimized for the selected range of

$28 \mathrm{M} 1+$ or M1 values (the latter also optimized for M2+) in 1D or 2D as required.

\section{Operating Model}

31 Population and fishing mortality at age: We applied the typical population survival

32 exponential model (Ricker 1975) with catches following the Baranov (1918)

33 equation, subject to a separable model of fishing mortality by age, year and seasonal

34 (half-year) fishery of the form:

$$
F_{a, y, p}=F_{r e f, y, p} \cdot S_{a, p}
$$

38 Where $F_{r e f, y, p}$ is the fishing mortality in year $\boldsymbol{y}$ and half-year fishery $\boldsymbol{p}$ for the age of

39 reference $(r e f)$, which in this study is age $2\left(F_{r e f, y, p}=F_{2, y, p}\right)$.

$40 S_{a, p}$ is the selectivity for each age typical of every half-year fishery and relative to the

41 age of reference (age 2), which is fixed at 1 (i.e. selectivity value of $S_{2, p}=1$ ).

42 Catches are modeled up to age 3+ (older ages are negligible) on a half-yearly basis.

$44 \quad$ Natural Mortality model: Natural mortality can be set common for all years and

45 ages (by setting a constant $\mathrm{M} 1+$ ) or varying between ages 1 and $2+$ by a common

46 factor, as follows:

$$
M_{2+}=M_{1} \cdot \text { Mfactor }_{2+}
$$

Mfactor $_{2+}$, if included, is estimated and kept constant across years. 
49 We checked the sensitivity of applying this factor to age 2 from the beginning of the

50 year or from July only.

51

52 The modeled average population during the spring period is tuned to the Acoustic

53 and DEPM spawning biomass and population at age estimates. The tuning indices

54 were used as relative (i.e. proportional to abundance by a catchability parameter $Q$ ).

55

56 Parameters: For an assessment covering the period 1987-2012 (including the first half

57 of 2013), we would have the following parameters for the 26 years (Y) of data: 4 for

58 the numbers at ages in the first year 1987 (ages 1-4, because the 3+ plus groups were

59 modeled as the sum of two age groups --3 and $4+), 26$ recruits at age $0(\mathrm{~N} 0, \mathrm{y})$,

$602 * 26+1$ for the fishing mortalities at the age of reference (age 2) (one per half year:

$61 \quad F_{2, y, 1}$ and $F_{2, y, 2}$ and $\left.F_{2,2013,1}\right), 5$ selectivities at age (the ages on a half-yearly basis: $S_{1,1}$

$\left.62 / S_{3,1} / S_{0,2} / S_{1,2} / S_{3,2}\right), 4$ Catchability parameters $(Q \cdot A c, Q \cdot D E P M$, and $Q \&$ Power for the

63 Juvenile index), and a minimum of 1 natural mortality $(\mathrm{M} 1+)=4+26+53+5+4+1=93$

64 parameters (or 94 if M1 and M2+ were estimated instead of single M1+).

66 Objective function: two objective functions were defined, one responding to the case

67 of assuming log-normal errors in all tuning data, which was based on a sum of

68 squared log residuals (similar to the Integrated Catch at age Analysis Patterson and

69 Melvin 1996), and the other for the case where age disaggregated observations (of

70 catches or from the spring survey abundance indexes) are split in a biomass

71 component (assuming log-normal error) and in percentages at age (assuming

72 multinomial errors). In the latter, the objective function was based on the log-

73 likelihood ratios (similar to the objective function in Stock Synthesis Model SS3 - 
74 Methot and Wetzel 2013). Parallel to the minimization of the objective function, the

75 log-likelihoods and the Akaike information criterion (AIC) were estimated for

76 comparison purposes (see below).

78 For the analysis assuming log-normal errors of all data catchability of surveys was

79 estimated common (equal) for all ages (flat catchability at age) but independently for

80 each survey, so that a single common catchability by survey is estimated. Both the

81 population in numbers at age and biomass (SSB) indices are used for the fitting.

82 However, the fitting to SSB indices do not require a catchability parameter, because

83 only the population at age estimates derived from the surveys are used to fit the

84 catchability by survey. Modeled SSB as estimated for a survey is just the product of

85 the modeled numbers at age estimates for the survey times the weights at age in the

86 population. In this way, consistency is assured between the catchability at age

87 estimates and SSB estimates for the surveys. In addition, the residual sum of squares

88 between modeled and observed biomass by the surveys contributes to the total fitting

89 even in the years when no age estimates from the surveys were available (as in 1994

90 and 1998 for the Acoustics or in $1996,1999 \& 2000$ for the DEPM). In turn, this

91 implies that the years when only a biomass index is provided by a survey do not

92 contribute to the fitting of the catchabilities at age. As such, 14 out of 16 acoustic

93 estimates are used for tuning the catchabilities at age (because the other 2 cruises

94 have no age index). For this same reason, only 19 out of 22 cruises tune the

95 catchability at age for the DEPM.

96 
97 The objective function is a sum of squared log residuals (SSQ) defined for the

98 tuning survey indices of biomass and population at age estimates and for the catches

99 at age and catches in tonnes of the different seasonal fisheries defined above.

100

101

WSSQTotal $=$

SSQCapt ${ }_{\text {age }}+$ SSQCapt $_{\text {weight }}+$ SSQSurveys ${ }_{\text {age }}+$ SSQSurveys $_{\text {weight }}$

Eq A.B.3

102 The SSQ of the catches in tonnes ( SSQCapt $t_{\text {wight }}$ ) are estimated as:

$103 \quad \sum_{1987}^{2013} \sum_{p=1}^{2} \lambda_{y, p} \cdot\left(\operatorname{Ln}\left(C_{y, p} / \hat{C}_{y, p}\right)\right)^{2}$

Eq A.B.4

104 Where the summation reaches the first half of year 2013 and suffix $\boldsymbol{p}$ refers to the

105 seasonal fishery (i.e. the first or second half of the year). The expected catches in

106 weight are just based on the SOPs (sum of products) of the modeled catches at age

107 and their observed mean weights.

108

109 In parallel the residuals to the catches at age (in numbers) (SSQCapt age $_{\text {e }}$ ) are

110 estimated as:

$111 \quad \sum_{a g e s}^{3+} \sum_{1987}^{2012} \sum_{p=1}^{2} \lambda_{a, y, p} \cdot\left(\operatorname{Ln}\left(C_{a, y, p} / \hat{C}_{a, y, p}\right)\right)^{2}$

112 Where modeled catches $\left(\hat{C}_{a, y, p}\right)$ are simply obtained from the Baranov equation

113 over the half-year period.

114

115 In addition, for DEPM and Acoustics population at age the estimates, the

116 SSQSurveys ${ }_{g e}$ are

117 SSQSurveys age $_{2}=\sum_{\text {ages }}^{3+} \sum_{\text {year }}^{2013} \sum_{s}^{\text {surveys }} \lambda_{a, y, s} \cdot\left(\operatorname{Ln}\left(U_{a, y, s} / \hat{U}_{a, y, s}\right)\right)^{2} \quad$ Eq A.B.6

118 Where the modeled index is estimated as: 
$119 \hat{U}_{a, y, s}=Q_{s} \cdot \hat{N}_{a, y, s}=Q_{s} \cdot \frac{\hat{N}_{a, y, p=1} \cdot e^{-\alpha_{v} \cdot Z_{a, y, p=1}}}{\left(\alpha_{s}-\omega_{s}\right) \cdot Z_{a, y, p=1}} \cdot\left(1-e^{-(\alpha-\omega) \cdot Z_{a, y, p=1}}\right)$

120 Where, suffix $\boldsymbol{s}$ refers to the Acoustic or DEPM surveys, suffix $\boldsymbol{p}=\mathbf{1}$ refers to the

121 first half of the year period; and $\boldsymbol{a}$ and $\boldsymbol{y}$ for age and year. $\boldsymbol{Z}$ is total mortality and

$122 \hat{N}_{a, y, s}$ the modeled population in numbers at survey time. And $\alpha_{s}-\omega_{s}$ are the

123 starting and ending time of the surveys (as fractions of the year). Notice that the

124 survey catchability $Q_{s}$ is common for all ages. Suffix $\boldsymbol{a}$ reaches for acoustics age 2+

125 until 1999 and subsequently to age 3+ as for the whole DEPM series.

126

127 And for the aggregate indices of acoustic or DEPM the SSQSurvey weight $_{\text {equals: }}$

$128 \sum_{\text {year }}^{2013 \text { surveys }} \lambda_{v} \lambda_{y, s} \cdot\left(\operatorname{Ln}\left(U_{y, s} / \hat{U}_{y, s}\right)\right)^{2}$

Eq A.B.8

129 With the modeled index estimated simply as the sum of products of the estimated

130 index by age by its observed mean weight in the population, as: 8

131

132

$$
\hat{U}_{y, s}=\sum_{\text {ages }} \hat{U}_{a, y, s} \cdot W_{a, y, s}^{\prime}
$$

where no additional catchability parameters appear.

135 Weighting factors: tuning data and fishery catches at age can be weighted (with the

136 lambda factors, $\lambda$ ): Fitting the catches (in tonnes) of the two halves of the year received equal weighting factors (lambda $=1$ ). Weighting factors for the catches at ages 1 to $3+$ were all set equal to 1 , but for age 0 it was set equal to 0.01 because

139 these catches are not considered to be actually separable (since they are taken

140 independently of the other ages and are very noisy). Weighting factors for the

141 DEPM and acoustics were set equal to 0.667 as used in ICA; this is made to 
142 discount for correlation across ages in the survey estimates as in the standard ICA

143 implementation. The survey biomass estimates by the model were fitted directly

144 without any differential weighting $(\lambda=1)$, therefore acting as a penalty when the

145 total sum of products of the modeled age structured values diverges from the

146 biomass observations.

147 We carried out a sensitivity analysis to the weighting factors applied to the indexes

148 at age from surveys for which all $\lambda_{a, y, s}$ were set at 1 (not shown in the paper). Such

149 alternative weighting result in negligible changes of the natural mortality estimates,

150 with changes smaller than $3 \%$ both in the estimates as in the range of the $95 \%$

151 confidence intervals.

152 The Log likelihood estimates ( $L L H)$ of the fitting to the (o) auxiliary series of $(n)$

153 observations, each subject to log-normal errors, was simply the sum over the

154 observation series of their respective $L L H_{\text {_observations }}$ :

$L L H_{\text {Oobservations }}=-\sum_{\text {years_ages }} \sum_{y, a} \cdot\left(\operatorname{Ln}\left(O_{y, a} / \hat{O}_{y, a}\right)\right)^{2} /\left(2 \cdot \sigma_{o}{ }^{2}\right)-n \cdot \ln \left(\sigma_{o} \sqrt{2 \cdot \pi}\right)$

157 Whereby the log standard error $\sigma_{o}$ by series was taken from the square root of the

158 weighted mean squared residuals for each auxiliary observation series.

160 For the analysis assuming multinomial errors of the age

161 All assumptions for the modeling were the same as for the sum of squared log

162 errors, except that for the age structure information from surveys and catches, which

163 are entered as percentages at age (in numbers), subject to multinomial errors. Model

164 fitting is achieved by maximization of the log-likelihood (using log-likelihood 165 ratios). 
167 The objective function is a sum of log-likelihood ratios defined for the tuning

168 survey indices of biomass and population at age estimates and for the catches at age

169 and catches in tons of the different seasonal fisheries defined above.

170

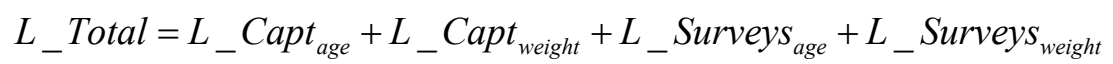

171

172 Where log-likelihood ratios for the catches in tonnes $\left(\right.$ Lapt $\left._{\text {weight }}\right)$ :

$173 \quad L_{-}$Capt $_{\text {weight }}=\sum_{1987}^{2013} \sum_{p=1}^{2} \lambda_{a, y, p} \cdot\left(\operatorname{Ln}\left(C_{y, p} / \hat{C}_{y, p}\right)\right)^{2} /\left(2 * C V c^{\wedge} 2\right) \quad$ Eq A.B. 12

174 Which extends the summation up to the first half of year 2013, with modeled 175 catches in weight based only on the SOPs (sum of products) of modeled catches.

176 Suffix $p$ refers to the first or the second half of the fisheries year. The assumed $C V C$

177 (equal to log-normal error $\sigma$ ) was 0.1 (i.e. consistent with our assumption of rather 178 precise catch reporting).

179 The log-likelihood ratios for the observed proportions at age in the catches in 180 numbers (LCapt age $)$ are:
$L_{-}$Capt $_{\text {age }}=\sum_{\text {ages year }}^{3+} \sum_{p=1}^{2013} \sum_{y, p}^{2} \cdot p_{a, y, p} \cdot \operatorname{Ln}\left(p_{a, y, p} / \hat{p}_{a, y, p}\right)$
Eq A.B. 13

which extends the summation until the first half of 2013. Suffix $p$ refers to the first or second half of the fisheries year. The modeled proportion of catches by ages ( $\left.\hat{p}_{a, y, p}\right)$ is directly deduced from the ratio of catches at age over the total catch in numbers. The equivalent random sampling size $\left(x_{y, p}\right)$ of available ages was assumed to be from 100 individuals of all the series of half-year catches (similar to 187 sampling levels adopted by default for the surveys). 
188 For the catches at age 0 , as they were considered not separable, a likelihood ratio

189 similar to equation A.B.12 above was applied to the observed over expected catches

190 at age 0 , assuming a $C V_{\text {age } 0}$ of 0.25 .

191

192 Similarly, the log-likelihood ratios for the Biomass indexes in tonnes (

193 L_Survey $\left.S_{\text {weight }}\right)$

194

$L_{-}$Surveys $S_{\text {weight }}=\sum_{1987}^{2013 \text { Surveys }} \sum_{s} \lambda_{y, s} \cdot\left(\operatorname{Ln}\left(U_{y, s} / \hat{U}_{y, s}\right)\right)^{2} /\left(2 * C V_{s}^{\wedge} 2\right) \quad$ Eq A.B. 14

195 with the modeled biomass index $\left(\hat{U}_{y, s}\right)$ is estimated as the sum of products of

196 modeled populations at age times the global (common) catchability across ages of

197 the surveys (given our Qflat model) and their mean weights at age (

$198 \sum_{a g e s} Q_{s} \cdot \hat{N}_{a, y, s} \cdot W_{a, y, s}^{\prime}$ ). Suffix $s$ is the survey index (referring to either the Acoustic

199 or the DEPM). The assumed $C V_{s}$ (equal to log-normal error) was 0.25 for both

200 surveys.

201

202 In addition, the likelihood ratios for the observed proportions at age in the survey

203 estimates $\left(\boldsymbol{p}_{a, y, s}\right)$ is estimated as

$204 L_{-}$Surveys ${ }_{\text {age }}=\sum_{\text {ages }}^{3+} \sum_{\text {year }}^{2013} \sum_{s}^{\text {Surveys }} x_{y, s} \cdot p_{a, y, s} \cdot \operatorname{Ln}\left(p_{a, y, s} / \hat{p}_{a, y, s}\right)$

206 And the modeled proportion at age estimate of the survey $\left(\hat{p}_{a, y, s}\right)$ derives from the

207 population at age indexes $\left(\hat{U}_{a, y, s}\right.$ of equation A.B.7) and is estimated as the ratio of

208 the modeled population at age $\left(\hat{N}_{a, y, s}\right)$ and the total modeled population (in 209 numbers during survey time). 
$211 \hat{p}_{a, y, s}=\frac{\hat{U}_{a, y, s}}{\sum_{\text {ages }} \hat{U}_{a, y, s}}=\frac{Q_{s} \cdot \hat{N}_{a, y, s}}{\sum_{\text {ages }} Q_{s} \cdot \hat{N}_{a, y, s}}=\frac{\hat{N}_{a, y, s}}{\sum_{\text {ages }} \hat{N}_{a, y, s}}$

213 Where suffix $\boldsymbol{s}$ is the survey index (to refer either the Acoustic or the DEPM), $\boldsymbol{a}$ and

$214 y$ stand for age and year respectively.

215 The equivalent random sampling size $\left(x_{y, s}\right)$ of available ages was assumed to be

216100 individuals for the acoustics series whilst ad hoc yearly sizes were estimated for

217 the DEPM which matched as closely as possible with the yearly reported CVs of the

218 proportions at ages from this survey series, as currently used for the ICES

219 assessment (ICES 2014). The ad hoc equivalent sizes for the DEPM ranged from 40

220 to 500 , with a mean of about 140 individuals. A sensitivity analysis was carried out

221 (not shown) to check the effect of reducing the equivalent sampling size to a

222 maximum of 66 individuals for all input data series of percentages at age, finding

223 out only relatively minor effects on the estimates of the natural mortality (by about

$2242 \%$ ), though certainly the range of the confidence intervals was increased at

225 sampling size 66 (by about $20-25 \%$ ).

227 No differential weighting factors for the components of the objective function were

228 applied for this second modeling of the observations, except for the weighting

229 factors of the catches at age 0 which were set equal to 0.01 since these catches are

230 not considered to be separable (this is because they are taken independently of the

231 other ages and are very noisy).

232 The log-likelihood estimates $(L L H)$ of the fitting to the (o) auxiliary series of $(n)$

233 observations each was simply the sum over the observation series (o) of every 
234 LLH_observations, which corresponded to either equation A.B.10 for those subject to

235 log-normal errors (catches in tons, surveyed estimates of total population in biomass

236 and the recruitment index) or to the following expression for the age disaggregated

237 observations subject to multinomial errors (catches and populations at age):

238

$L L H_{\text {_observations }}=\sum_{\text {years }} \ln \left(\frac{x_{y, t}}{x_{y, 1} ! \cdot x_{y, 2} ! \cdot x_{y, 3+} !} \cdot \hat{p}_{y, 1}^{x_{y, 1}} \cdot \hat{p}_{y, 2}^{x_{y, 2}} \cdot \hat{p}_{y, 3+}^{x_{y, 3+}}\right)$

239 Whereby the $x_{y, t}$ corresponds to the assumed equivalent random sampling size in

240 year $y$ for the auxiliary age disaggregated observation, as described above, and the

$241 x_{y, a}$ to the respective numbers at age as deduced from the observed percentages at

242 age (as $x_{y, a}=x_{y, t} \cdot p_{y, a}$, rounded) and finally the $\hat{p}_{y, a}$ correspond to the expected

243 percentages at age according to the modeling, as described above. 